\title{
Environmental impact of the main household cooking systems-A survey
}

\author{
Alessio Cimini and Mauro Moresi* \\ Department of Innovation in Biological, Agrofood and Forestry Systems, University of Tuscia, Viterbo, Italy
}

*Corresponding Author: Mauro Moresi, Department of Innovation in Biological, Agrofood and Forestry Systems, University of Tuscia, Viterbo, Italy. Email: mmoresi@unitus.it

Received: 9 January 2022; Accepted: 4 February 2022; Published: 23 February 2022

(C) 2022 Codon Publications

\section{OPEN ACCESS (c) (1)(2) (2)}

REVIEW ARTICLE

\begin{abstract}
The food cooking energy may represent the primary hotspot in the cradle-to-grave life cycle of several foods and drinks. It is mainly affected by the type of food and its cookery method, cooking appliance and the fuel selected as well as the number of portions to be cooked. The primary aim of this survey was to demonstrate the basic characteristics of the main cooking methods, appliances, and fuels as well as energy required for some key foods. The secondary aim was to assess the environmental impacts of a generic cooking system as a function of few household cookers fueled by different fuels (i.e., firewood, charcoal, coal, natural gas, liquefied petroleum gas, kerosene and biogas) and electricity in the Italian scenario by using the ReCiPe 2016 and product environmental footprint (PEF) standard methods and Ecoinvent v. 3.7 database. A functional unit equal to per capita useful energy delivered to the pot for cooking (1.41 gigajoule [GJ]) in 27 European Union countries in 2019 was used as the basis of comparison. The use of natural gas resulted in minimum impact in nine of the 18 mid-point impact categories of ReCiPe 2016 method and two damage categories (human health and ecosystem quality) with a minimum overall weighted damage score $\left(\mathrm{OWDS}_{\mathrm{R}}\right)$ of $\sim 5 \mathrm{Pt}$. Thus, such a cookstove appeared to be more apt to minimize both indoor and outdoor air pollution. Even if the electric cookstove yielded a greater $\operatorname{OWDS}_{\mathrm{R}}(8.6 \mathrm{Pt})$ because the Italian electricity grid mix was mainly based on fossil sources, it was possible to forecast that new-generation, smart cooktops driven by hydro- and wind-power electricity would minimize $\mathrm{OWDS}_{\mathrm{R}}$ to as low as 0.9 and 1.4 Pt, respectively, thus not only avoiding the consumption of any fossil energy source but also improving people's health.
\end{abstract}

Keywords: clean cooking, cooking appliances, cooking fuels, cooking systems, environmental impacts, life cycle assessment, PEF standard method, ReCiPe 2016 standard method

\section{Introduction}

Nowadays, cooking of food has become mandatory for humans (Wrangham and Conklin-Brittain, 2003). Its associated energy requirements represent the preponderant share of energy used in the cradle-to-grave life cycle of several foods and drinks, as in the case of vegetal products with low to medium degree of processing (Carlsson-Kanyama and Boström-Carlsson, 2001), dry pasta (Bevilacqua et al., 2007; Cimini et al., 2019, 2021a, 2021b) and coffee brewing (Cibelli et al., 2021). Energy use for cooking is largely affected by the food type and its cookery method, and the cooking appliance selected. Energy utilization reduces as the number of portions cooked increases (Carlsson-Kanyama and BoströmCarlsson, 2001).

About one-third of the human population (that is 2.5-billion people), generally living in low- and middle-income countries, still relies on solid biomass fuels (i.e., firewood, crop residue, charcoal and dung) for cooking, while the remaining 5-billion people rely on fossil energy, such as coal, natural gas (NG), kerosene, liquefied petroleum gas (LPG) and electricity (Wright et al., 2020). 
The combustion products emitted by solid fuels give rise to by far higher levels of indoor air pollution than those recommended by the World Health Organization (WHO, 2018), especially in poorly ventilated dwellings. These harmful emissions have been associated with respiratory diseases and other health problems (i.e., lung cancer, chronic obstructive pulmonary disease [COPD], pneumonia, tuberculosis, cardiovascular events, low birth weight and cataracts; Fullerton et al., 2008), and are responsible for as many as 4 million premature deaths per year globally (WHO, 2021). WHO is thus committed to attaining the so-called 'Sustainable Development Goals' (SDG) on health (SDG 3) and energy (SDG 7) as scheduled by the United Nations Development Program (UNDP, 2021) in order to improve the health and well-being of the people still using polluting technologies and fuels not only for cooking but also for heating and lighting. So far, numerous programs have been implemented globally to introduce cleaner and more efficient cooking technologies. All the attempts to improve the performance of biomass-burning stoves have until now caused limited health benefits, while the use of other cleaner fuels (i.e., LPG, ethanol and biogas) has offered not only greater health benefits but also smaller greenhouse gas (GHG) emissions (Rosenthal et al., 2018). In particular, the replacement of solid biofuels with LPG was quite successful in several countries, such as Brazil (Wright et al., 2020), Ecuador (Martínez-Gómez et al., 2016), Ghana (Afrane and Ntiamoah, 2011, 2012), Indonesia (Thoday et al., 2018), India (Gould and Urpelainen, 2018; Jungbluth et al., 1997; Singh et al., 2014), and a few countries of the Indo-Chinese Peninsula (Aberilla et al., 2020) for at least two reasons: (i) lower GHG emissions compared to burning solid fuels, and (ii) lower infrastructure requirement compared to NG and electricity (Wright et al., 2020). Unfortunately, although use of such a clean cooking technology improves people's health conditions, it still relies on fossil energy sources. A long-term sustainable cooking should alternatively rely on renewable energy sources only (i.e., solar or wind energy, biogas and bioethanol; Aro, 2016).

Several life cycle assessment (LCA) studies have so far dealt with cooking appliances, such as cookstoves fired by different fuels (Aberilla et al., 2020; Afrane and Ntiamoah, 2011, 2012; Jungbluth et al., 1997; Singh et al., 2014), induction and gas hobs (Favi et al., 2018) and electric and gas ovens (Landi et al., 2019) in the Italian context as well as induction hobs with different electronic boards (Elduque et al., 2014), using diverse life cycle impact assessment (LCIA) methods, some of which, unfortunately, use old databases.

The primary aim of this survey was to review the basic characteristics of main cooking methods, appliances and fuels as well as energy requirements for some key foods. The secondary aim was to account for a generic cooking system capable of delivering the useful per capita energy transferred to the cooking pot in 27 European Union (EU) countries in 2019 (Eurostat, 2021a). The final goal of this study was to assess its life cycle environmental impacts by using the well-known ReCiPe 2016 (Huijbregts et al., 2016) and product environmental footprint (PEF) (European Commission [EC], 2018b) LCIA methods and Ecoinvent v. 3.7 database (Ecoinvent, 2020). By using different fuels (i.e., firewood, charcoal, coal, NG, LPG, kerosene, and biogas) and electricity used in the Italian scenario, it was possible to identify the cooking system with overall minimum environmental impact and, thus, prospect promising new eco-smart household cooktops.

\section{Basic Characteristics of Main Cooking Methods}

Cooking makes food as more edible, easily digestible and relishing. In this way, cooked foods exhibit quite significant variations in their physical aspect, structure, composition and nutritional value. Any food-cooking operation is characterized by a heating element (i.e., open flame etc.) and a heat transfer medium that allows cooking by:

1. expansion if the hot medium is made of water or oil, and

2. concentration if the heating element transmits heat to food through a pan, plate or grill.

Mixed cooking methods include both modes. Generally, the first part of cooking is carried out by concentration, while the second one by expansion, thanks to the addition of a liquid. Alternatively, the dry heat cookery methods (i.e., baking, steaming, grilling and roasting) can be discriminated from the moist heat cookery ones (i.e., boiling, stewing, shallow frying, deep frying and basting). In the former, the heating element conveys heat directly to the food (which in turn is cooked in its own juice and the steam generated by the evaporation of water added to the food during its preparation) mainly by means of convection and/or irradiation. On the contrary, in the moist heat methods a liquid medium (i.e., water, milk, coconut cream, molted butter, oil etc.) is heated before or after the food to be cooked is placed in the cooking pan.

Table 1 briefly describes both basic cooking methods and some combined and microwave cooking methods by pointing out heat propagation media, range of cooking temperature and main heat transfer modes. 


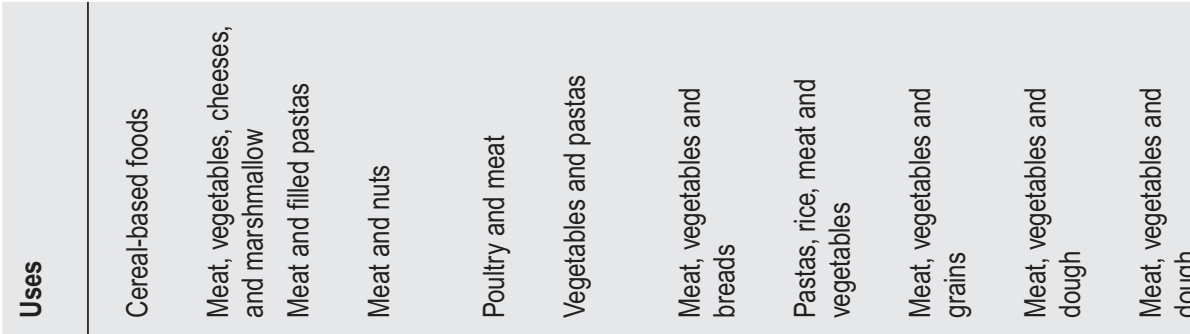

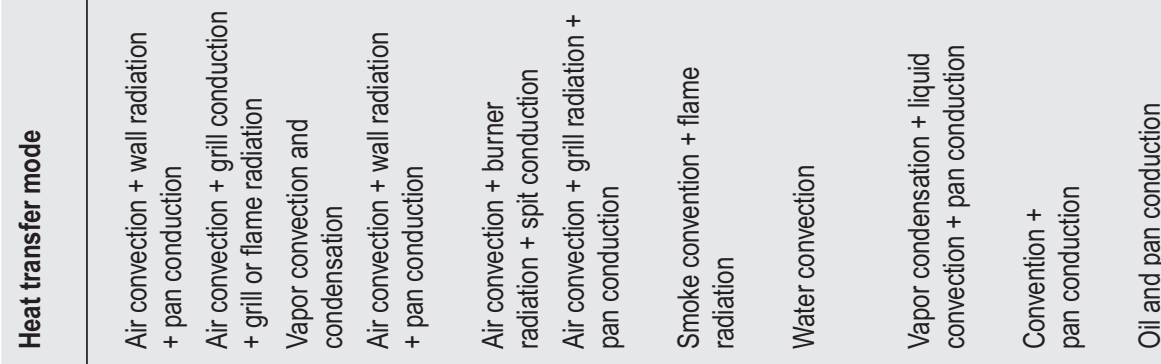

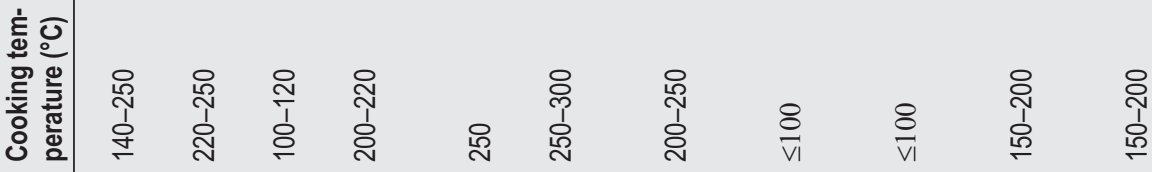

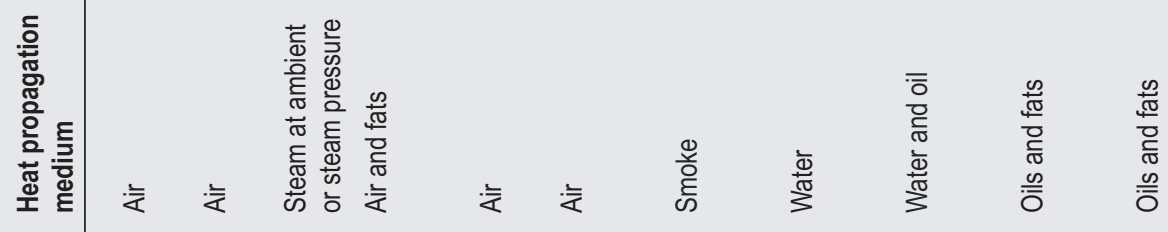

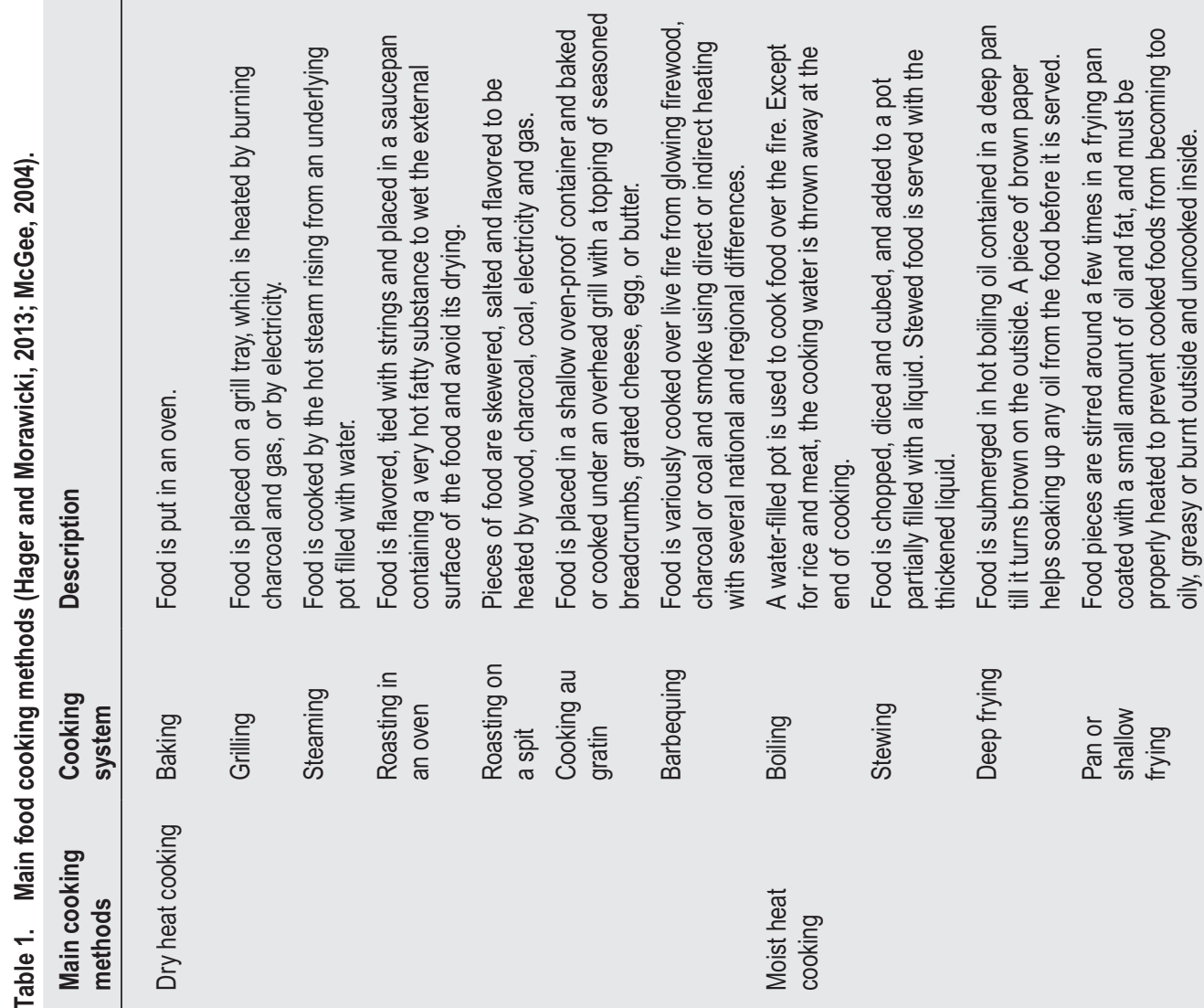




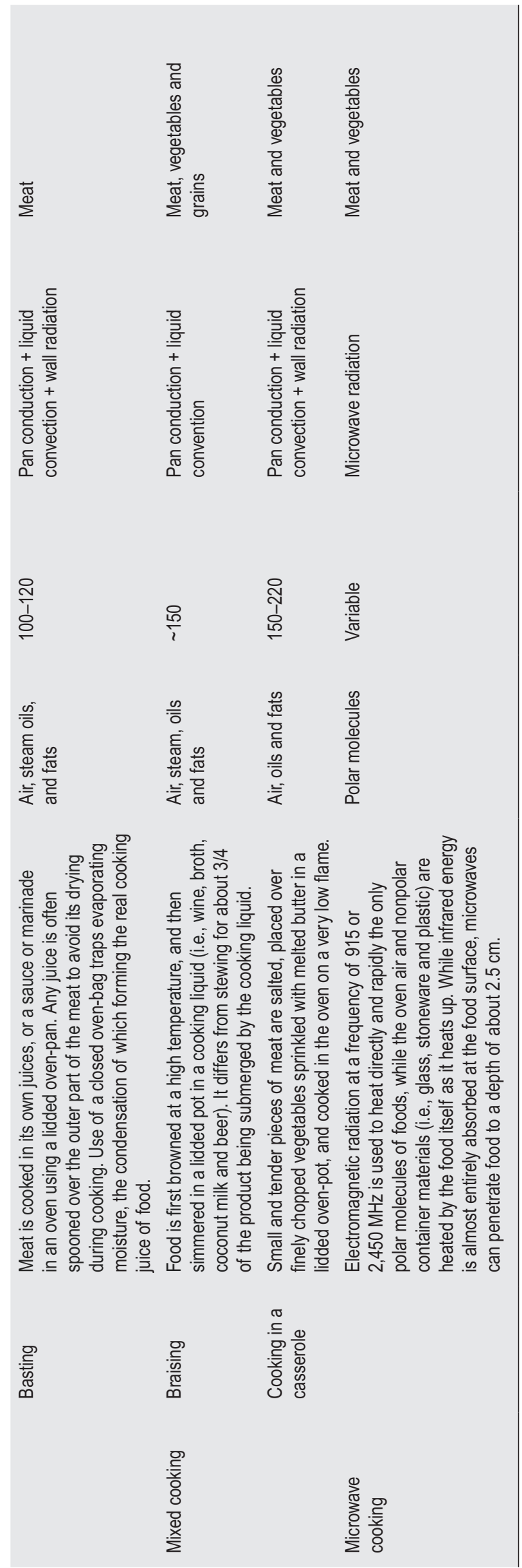

\section{Main cooking appliances}

Open wood fires were used for cooking by humans for approximately two million years (Wrangham, 2009). The energy performance and resulting emissions from biomass cookstoves depend on various factors, such as the stove design, fuel feeding practice, lighting, and combustion temperature (Okino et al., 2021; Rasoulkhani et al., 2018). Generally, traditional biomass stoves, largely used indoor in developing nations, are improperly ventilated, which leads to a significant increase in indoor levels of particulate matters $\left(\mathrm{PM}_{2.5}\right)$ and carbon monoxide that cause lung inflammation and lead to chronic obstructive pulmonary disease. Excessive consumption of biomass fuels has led to natural forest degradation and deforestation, as already observed in South Italy during period of Roman Empire, as well as shortage of firewood for cooking in some areas of Africa even today (Okino et al., 2021). In order to improve the efficiency of cooking energy and thus reduce the biomass consumption of the so-called three-stone fire stove, quite numerous improved stoves have been developed (Okoko et al., 2018; Wikipedia, 2021a). For instance, Darlami et al. (2019) reported that the thermal efficiency $\left(\eta_{\mathrm{CS}}\right)$ of a traditional Nepalese cookstove increased from $18.0 \%$ to $25.6 \%$ when it was modified with mud, while Okino et al. (2021) improved the thermal efficiency $\left(\eta_{\mathrm{CS}}\right)$ of a cooking stove insulated with sawdust from $13-21 \%$ to $19-35 \%$ with the use of a few indigenous wood fuels available in Uganda. Nevertheless, a recent review has found that the use of such improved cookstoves has so far had a small mitigating effect on the health results of household air pollution and called for more initiatives and policies to favor the adoption of cleaner fuels and improved cookstoves in households (Pratiti et al., 2020). In fact, more than 2.5-billion people in developing countries are still relying on quite polluting cooking fuels, such as wood, crop residues, animal dung, charcoal, coal and kerosene.

For instance, wood and coal burning cookstoves are still manufactured by the Amish in Lancaster County (PA, USA) to satisfy not only cooking and baking requirements but also heating and hot water requirements. In India (Jungbluth et al., 1997) and Nigeria (Anozie et al., 2007), kerosene stoves replaced most of the traditional biomass cookstoves, thanks to governmental fuel subsidies to prevent deforestation for cooking fuels. Cheaper and more efficient gas stoves fueled by NG and LPG started to disseminate once a distribution network for gas pipeline and bottled LPG transport was available. This allowed their increasing diffusion either in Europe or the United States since the beginning of the 20th century. Gas ignition was originally done by matchsticks. Then it became possible with a pilot light, a continuously burning gas flame under the cooktop to immediately light the gas leaving the burner if the stove was 
turned on. Nowadays, gas stoves have electronic ignition to avoid any gas consumption when the stove is not used, a flame failure device to stop gas flowing without igniting and prevent from accidental explosion, and an extractor hood to evacuate fumes and minimize indoor air pollution (Wikipedia, 2021b).

By the end of the 19th century, several electric stoves were patented in Canada, the United States and Australia, even though their diffusion in household kitchens was conditioned by the extension of urban and rural electrification. Whereas gas cooktops heat food with flame and disperse much of the heat in the air, electric cooktops mainly transfer heat to the cooking surface and thus are more efficient than gas cooktops. Electric cooktops include both open coil and smooth (or radiant) cooktop types. The former is made of resistive wires encased in hollow metal tubes arranged in a spiral to directly support the cookware, and thus is quite affordable and durable. On contrary, smooth and radiant types consist of a hotplate surface or a smooth glass-ceramic surface heated locally via electrical heating coils or halogen lamps. The latter guarantees less heat loss with easier cleanability but, unfortunately, higher stretchability and breakability. Nowadays, in such cooktops, the maximum temperature of the heating element is controlled thermostatically while power supply is regulated either discretely or continuously between minimum and maximum heat settings (Wikipedia, 2021c). Different studies have indicated that hotplates are least efficient among electric stoves (Hager and Morawicki, 2013), even if the glass-ceramic cooktops are found to be up to $20 \%$ less efficient than hotplate surfaces (Carlsson-Kanyama and Böstrom-Carlsson, 2001). Moreover, reflective trays beneath electric coils in coiled cooktops appeared to increase the energy efficiency and reduce heating period by 20\% (Hager and Morawicki, 2013). Induction stoves are de facto the latest version of electric stoves. In fact, these use electricity to generate electromagnetic induction in just ferromagnetic cookware, which is thus directly heated instead of being heated by beneath smooth surface of glassceramic. Such cooktops are not only highly safe but also the most energy-efficient appliances. Their accurate control of cooking temperature could be improved by using a low-cost, open-source electronic platform pilotable via smartphone, as in the case of the novel home ecosustainable pasta cooker previously developed by Cimini et al. (2020).

Among the diverse renewable fuel stoves, it is worth citing the biogas, ethanol and solar stoves.

Biogas stoves resemble the conventional NG and LPG stoves with just some modifications in burner design to maximize their combustion effectiveness and reduce unburned methane and soot from incomplete combustion (International Renewable Energy Agency [IRENA], 2017).

Alcohol burning stoves are like existing kerosene stoves, their main differences being related to the use of stainless steel to minimize corrosion and fuel type used. Interest for such stoves is mainly due to the use of bioethanol, its combustion practically providing pollutant-free emissions. Unfortunately, such stoves are expensive and suffer from the costs of bioethanol supply chain. In the EU, such stoves are used for marine and mobile leisure applications in conjunction with an aqueous mixture of $85 \%$ (v/v) ethanol. Their use was extended to a few developing countries, especially in Brazil, where the above mixture is available as a biofuel (Benka-Coker et al., 2018; Stokes and Ebbeson, 2005; Zuzarte, 2007). In order to avoid using such an inflammable mixture, other safer prototypes were developed in India and South Africa to utilize diluted ethanol mixtures at 50\% (v/v) (Rajvanshi et al., 2004) or enriched with colorants and thickeners (i.e., calcium acetate) and flavoring agents (Greengel; Climate Technology Center \& Network [CTCN], 2017; Okusanya et al., 2019), respectively.

Solar cooking appliances started to be commercialized in the 1980 s as $100 \%$ emission-free devices capable of concentrating solar thermal energy to cook foods. Each one consists of three components: concentrator, absorber and retainer. The first one, being made of shiny materials, such as silver, chromium or aluminum, allows the sunlight to be concentrated at a fixed point, where it is absorbed by a black-painted cookware to cook food. To minimize heat loss, the cookware is to be properly insulated and lidded. Four types of solar cookers are currently available (Pandey et al., 2021), as shown in Table 2. The box cooker simply consists of a box inside another one and is the cheapest type of solar cooker. The transparent cover on the top of the outer box allows entrance of the sunlight, where it is absorbed by the black-painted inner box. A mirror in the inner side of the outer box helps in reflecting the heat energy radiated from the inner black box. The panel solar cooker has a large flat panel, which mainly reflects and focuses the sunlight falling vertically on the cooker for cooking. Owing to the instability of panel to high wind, such a solar cooker is not used frequently. The parabolic solar cooker collects the solar radiation in the central focus point of a collector dish, where a pressure cooker with black-painted bottom is placed. In this way, temperatures as high as those causing the burning of food can be achieved. Finally, the vacuum-tube solar cooker entails two tubes, one inside the other. The inner tube contains food to be cooked and is black painted to maximize heat absorption, while the outer one is transparent. Vacuum is created in the space between these tubes to minimize heat loss and trap the heat absorbed for a longer period. Such type of cooker is highly efficient (Pandey et al., 2021). 
Table 2. Main types of cookstoves and performances together with cooking fuels used, some typical models, fuel availability and cookstove efficiency $\left(\eta_{\mathrm{cs}}\right)$.

\begin{tabular}{|c|c|c|c|c|c|}
\hline Category & Fuel type used & Some typical models & Fuel availability & $\eta_{\mathrm{CS}}(\%)$ & References \\
\hline \multirow[t]{3}{*}{$\begin{array}{l}\text { Traditional } \\
\text { biomass stove }\end{array}$} & Firewood & & $\begin{array}{l}\text { Usually, easily } \\
\text { available in situ }\end{array}$ & $\begin{array}{l}11 \\
13.5 \\
14 \\
17 \\
20 \\
13-21\end{array}$ & $\begin{array}{l}\text { Aberilla et al., } 2020 \\
\text { Singh et al., } 2014 \\
\text { Afrane and Ntiamoah, 2011, } 2012 \\
\text { Hager and Morawicki, } 2013 \\
\text { Benka-Coker et al., } 2018 \\
\text { Okino et al., } 2021\end{array}$ \\
\hline & Crop residues & & $\begin{array}{l}\text { Usually easily } \\
\text { available in situ }\end{array}$ & 11 & $\begin{array}{l}\text { Singh et al., } 2014 \\
\text { Aberilla et al., } 2020\end{array}$ \\
\hline & Charcoal & & Supply chain required & $\begin{array}{l}14 \\
17.5 \\
18 \\
23 \\
24-32\end{array}$ & $\begin{array}{l}\text { Aberilla et al., } 2020 \\
\text { Singh et al., } 2014 \\
\text { Afrane and Ntiamoah, 2011, } 2012 \\
\text { Benka-Coker et al., } 2018 \\
\text { Okoko et al., } 2018\end{array}$ \\
\hline Coal stove & Coal & & Supply chain required & 15.5 & Singh et al., 2014 \\
\hline $\begin{array}{l}\text { Improved } \\
\text { biomass stove }\end{array}$ & Firewood & & $\begin{array}{l}\text { Usually, easily } \\
\text { available in situ }\end{array}$ & $25.0-42.8$ & Mehetre et al., 2017 \\
\hline \multirow[t]{3}{*}{$\begin{array}{l}\text { Modern fossil } \\
\text { fuel stove }\end{array}$} & Kerosene & & Supply chain required & $\begin{array}{l}35 \\
40 \\
45 \\
46 \\
47 \\
42-64\end{array}$ & $\begin{array}{l}\text { Afrane and Ntiamoah, } 2012 \\
\text { Benka-Coker et al., } 2018 \\
\text { Hager and Morawicki, } 2013 \\
\text { Aberilla et al., } 2020 \\
\text { Singh et al., } 2014 \\
\text { Jungbluth et al., } 1997\end{array}$ \\
\hline & LPG & & Supply chain required & $\begin{array}{l}24-34 \\
45 \\
46^{*} \\
49 \\
50 \\
56 \\
57 \\
60-72\end{array}$ & $\begin{array}{l}\text { Cimini and Moresi, } 2017 \\
\text { Afrane and Ntiamoah, } 2012 \\
\text { Cimini and Moresi, } 2017 \\
\text { Aberilla et al., } 2020 \\
\text { Hager and Morawicki, } 2013 \\
\text { Benka-Coker et al., } 2018 \\
\text { Singh et al., } 2014 \\
\text { Afrane and Ntiamoah, } 2011 \\
\text { Jungbluth et al., } 1997\end{array}$ \\
\hline & Natural gas & & $\begin{array}{l}\text { Supply infrastructure } \\
\text { required }\end{array}$ & 50 & Hager and Morawicki, 2013 \\
\hline \multirow[t]{4}{*}{ Electric stove } & Electricity & Generic electric stove & $\begin{array}{l}\text { Supply infrastructure } \\
\text { required }\end{array}$ & $\begin{array}{l}55 \\
59 \\
65 \\
70 \\
80\end{array}$ & $\begin{array}{l}\text { Benka-Coker et al., } 2018 \\
\text { Aberilla et al., } 2020 \\
\text { Afrane and Ntiamoah, } 2012 \\
\text { Singh et al., } 2014 \\
\text { Hager and Morawicki, } 2013\end{array}$ \\
\hline & & (a) Hotplate hob & & $\begin{array}{l}42-50 \\
57^{*}\end{array}$ & Cimini and Moresi, 2017 \\
\hline & & (b) Coil stove & & 49 & Wollele, 2020 \\
\hline & & (c) Induction cooktop & & $\begin{array}{l}27-39 \\
65^{*} \\
45-59 \S \\
66-68^{\#}\end{array}$ & $\begin{array}{l}\text { Cimini and Moresi, } 2017 \\
\text { Cimini et al., } 2020\end{array}$ \\
\hline \multirow[t]{3}{*}{$\begin{array}{l}\text { Renewable } \\
\text { fuel stove }\end{array}$} & Biogas & & Supply chain required & $\begin{array}{l}55 \\
50\end{array}$ & $\begin{array}{l}\text { Singh et al., } 2014 \\
\text { Aberilla et al., } 2020 \\
\text { Afrane and Ntiamoah, 2011, } 2012\end{array}$ \\
\hline & Ethanol & $\begin{array}{l}\text { (a) Low-grade ethanol } \\
\text { stove } \\
\text { (b) Ethanol-gel stove }\end{array}$ & Supply chain required & $\begin{array}{l}43-45 \\
55 \\
43\end{array}$ & $\begin{array}{l}\text { Rajvanshi et al., } 2004 \\
\text { Benka-Coker et al., } 2018 \\
\text { Okusanya et al., } 2019\end{array}$ \\
\hline & Solar & $\begin{array}{l}\text { (a) Box cooker } \\
\text { (b) Panel cooker } \\
\text { (c) Parabolic cooker } \\
\text { (d) Vacuum tube cooker }\end{array}$ & Weather-dependent & $\begin{array}{l}20 \\
26.6\end{array}$ & $\begin{array}{l}\text { Hager and Morawicki, } 2013 \\
\text { Arenas, } 2007 \\
\text { Xu et al., } 2015\end{array}$ \\
\hline
\end{tabular}

"As referred to dry pasta cooking with a water-to-pasta ratio (WPR) of $10 \mathrm{~L} / \mathrm{kg}$ when using the environmentally sustainable cooking practice set up by Cimini and Moresi (2017).

\#As referred to dry pasta cooking with WPR $=10 \mathrm{~L} / \mathrm{kg}$ when using the home eco-sustainable pasta cooker (Cimini et al., 2020).

$\S$ As referred to dry pasta cooking with the minimum WPR of 2-4 L/kg when using the home eco-sustainable pasta cooker (Cimini et al., 2020). 
Table 2 provides an overview of main cooking stoves in use together with the cooking fuels used, fuel availability and cookstove efficiency $\left(\eta_{\mathrm{CS}}\right)$.

Besides the cooking stoves mentioned above, useable for the so-called surface (or stovetop or cooktop) cooking, oven cooking, must also be considered, since it is essential for cooking quite numerous food products (i.e., bread, cakes, biscuits and various meat products) requiring diverse cooking methods, such as baking, grilling, roasting etc. (Table 1). An oven is a device liable to expose foods to a hot environment. It consists of a hollow chamber that can be heated in a controlled manner using a burning gas, electricity or microwaves. When an oven is combined with cook-tops (range), the fuel used for the oven may be the same as, or different from, that used for the burners on the stovetops. Generally, the food placed in an oven is heated from below, as in the case of baking and roasting. It can be also heated from the top, as in the case of broiling and grilling. In a conventional oven, the air is naturally circulated in the oven chamber, while in a convection oven, air recirculation is assisted by a small fan, thus resulting in faster and more energy-efficient cooking of food. Such ovens make use of a thermostat for on and off mode in order to maintain about constant the temperature selected, and a timer to turn off the oven automatically after selected period. The so-called smart ovens may use computer-based controls to program quite different cooking modes and even the possibility of automatically shutting it off when the minimum core temperature of the food has been attained. Moreover, self-cleaning ovens are earning an increasing popularity among consumers, their manual cleaning being complicated and asking for critical cleaning chemicals. There are two types of self-cleaning ovens (Barratt, 2021; Hager and Morawicki, 2013):

(i) Pyrolytic ovens, which feature a self-cleaning mode that heats the oven to about $500^{\circ} \mathrm{C}$ for as long as $2 \mathrm{~h}$ to convert food and fat residues into a white ash that can be wiped away easily.

(ii) Catalytic ovens, their porous surfaces being embedded with catalysts, which oxidize residual food by converting it into ash during cooking of food.

Currently, the pyrolytic version of self-cleaning ovens is not only that most widespread since it needs no expensive catalyst (Hager and Morawicki, 2013), but also because it is more thermally efficient due to greater wall insulation density required to withstand the high self-cleaning temperatures used. Generally, the thermal efficiency $\left(\eta_{\mathrm{CS}}\right)$ of well-insulated conventional electric ovens ranges from $10 \%$ to $15 \%$, while that of gaseous counterparts ranges from $6 \%$ to $7 \%$ because of the higher air flows and electric glow-bar that run continuously to reignite the gas flame should it blow out (Barratt, 2021; Hager and Morawicki,
2013). The energy requirements of convection ovens are less than those of conventional ovens by 20-30\% (Barratt, 2021). Finally, the mean efficiency of a microwave oven was reported to range between 56\% and 60\% depending on the class of microwave (Hager and Morawicki, 2013), although efficiency of as low as $35 \%$ was reported by Probert and Newboroug (1985).

In addition to the above oven types, it is necessary to acknowledge wood-fired ovens, which are used globally in restaurants, rotisserie shops and bakeries. For instance, about 6,400 pizza restaurants are operating in the city of São Paulo in Brazil and using about 48 megagram $(\mathrm{Mg}) /$ year of wood as fuel in their pizza ovens. These are responsible for an average emission factor of $\mathrm{PM}_{2.5}=0.38 \mathrm{~g}$ per $\mathrm{kg}$ of wood burned (Lima et al., 2020). The average $\mathrm{PM}_{2.5}$ concentration at the exit of their chimneys was quite high $\left(6,171 \mu \mathrm{g} / \mathrm{m}^{3}\right)$, while indoor, it was about two orders smaller in magnitude $\left(68 \mu \mathrm{g} / \mathrm{m}^{3}\right)$ (Lima et al., 2020), although it definitively exceeded the indoor 24-h mean level of $15 \mu \mathrm{g} / \mathrm{m}^{3}$ of $\mathrm{PM}_{2.5}$ recommended by WHO (2018). In order to limit such a high $\mathrm{PM}_{2.5}$ emission in Delhi (India), it was proposed to replace coal-fired with electric- and gas-fired appliances in all restaurants with a seating capacity of more than 10 persons (Apurva, 2016). Also, San Vitaliano, a town with a population of 5,000 people located near Naples (Italy), banned the use of wood-fired ovens in restaurants and bakeries during the cold season unless their chimneys were equipped with pollution-reducing filters (Singh and Highway, 2016). However, wood-fired ovens are specifically used to bake the well-known Pizza Napoletana (TSG), registered as a traditional specialty guaranteed by the EC (2010) Regulation No. 97/2010. Such ovens consist of a base of tuff bricks covered with a circular cooking floor over which is built a dome made of refractory materials to minimize heat dispersion. Their appropriate geometric dimensions (i.e., mouth of an having a width of 45-50 cm and a height of 22-25 cm, a cooking floor with a diameter of $105-140 \mathrm{~cm}$ and a vault height of $40-45 \mathrm{~cm}$ ) allow the temperature of the dome and cooking floor maintained at about $485^{\circ} \mathrm{C}$ and $430{ }^{\circ} \mathrm{C}$, respectively; this ensures the baking quality of the Pizza Napoletana TSG (EC, 2010).

The thermal efficiency $\left(\eta_{\mathrm{CS}}\right)$ of such ovens should be like that of conventional gas ovens. According to Igo et al. (2020), the thermal efficiency of a metal fired-wood oven to heat 20 liters of water from 35 to $90^{\circ} \mathrm{C}$ was found to be of $\sim 19 \%$, about $55 \%$ of the energy consumed being lost by hot fumes and $26 \%$ dispersed through the oven walls. Alternatively, the specific consumption of two types (indirect and semi-direct) of bakery ovens resulted in 0.55 and $0.90 \mathrm{~kg}$ of wood used per $\mathrm{kg}$ of wheat flour baked, respectively (Manhiça et al. 2012). This was equivalent to an estimated oven efficiency of $3-5 \%$ when assuming an increment in temperature from 25 to $150^{\circ} \mathrm{C}$ 
for dough having a moisture content of $36.5 \%(\mathrm{w} / \mathrm{w})$ and the lower heating value of firewood as shown in Table 3.

\section{Cooking fuels}

According to Eurostat (2021a), the final energy consumption in households in EU-27 in 2019 amounted to about $10.3 \times 10^{18} \mathrm{~J}, 63.6 \%$ of which was used for space heating, $14.8 \%$ for water heating, $14.1 \%$ for lighting and appliances, $6.1 \%$ for cooking devices and $0.4 \%$ for space cooling. The share of energy consumption for cooking ranged from 1\% in Finland to as much as 36\% in Portugal, while it was $6.5 \%$ in Italy. The cooking energy consumption in EU-27 was mainly supplied by electricity (49.8\%), gas (31\%), oil and petroleum products (13\%), renewables and wastes (5.7\%) and solid fuels (0.6\%). In Italy, it was primarily supplied by gas (69.2\%), then by electricity $(15.8 \%)$, oil and petroleum products $(10.2 \%)$ and renewables and wastes (4.8\%).

The specific energy consumption for cooking was thus estimated by referring the overall cooking energy consumed in 2019 (628.67 petajoule [PJ]) by EU-27 population ( 447 million) (Eurostat, 2021b), and it amounted to about 1.41 gigajoule [GJ] (i.e., $391 \mathrm{kWh}$ ) per capita/year.

The main characteristics of the cooking fuels used globally are shown in Table 3.

\section{Biomass fuel}

The use of biomass as a fuel in thermal and electrical applications is related to the fact that its combustion is $\mathrm{CO}_{2}$ neutral that is, $\mathrm{CO}_{2}$ released into the air equals to that absorbed during photosynthesis. The ultimate composition of wood biomass is slightly dependent on species. Roughly, it is made of $50 \%$ carbon, $6 \%$ hydrogen, $44 \%$ oxygen and $0.1-0.5 \%$ nitrogen (Vassilev et al., 2010). Such composition may vary in other agricultural residues (i.e., rice husk, straw, cotton stalk and grasses), mainly because of higher hemicellulose and ash contents (Shen et al., 2010). Ash is an inorganic fraction of biomass fuel that remains after its burning, and it includes calcium, potassium, sodium, magnesium and other elements. The heating value of biomass is often expressed as the higher (HHV) and lower (LHV) heating values, provided the heat released by its complete combustion leading to the production of water vapors includes or does not include the latent heat of water condensation. Such values decrease as the initial moisture content of biomass increases. These can be determined experimentally via an adiabatic bomb calorimeter or predicted based on the weight fraction of carbon $\left(x_{C}^{\prime}\right)$, hydrogen $\left(x_{H}^{\prime}\right)$, oxygen $\left(x^{\prime}\right)$ and moisture content $\left(x_{M}\right)$ of the biomass under

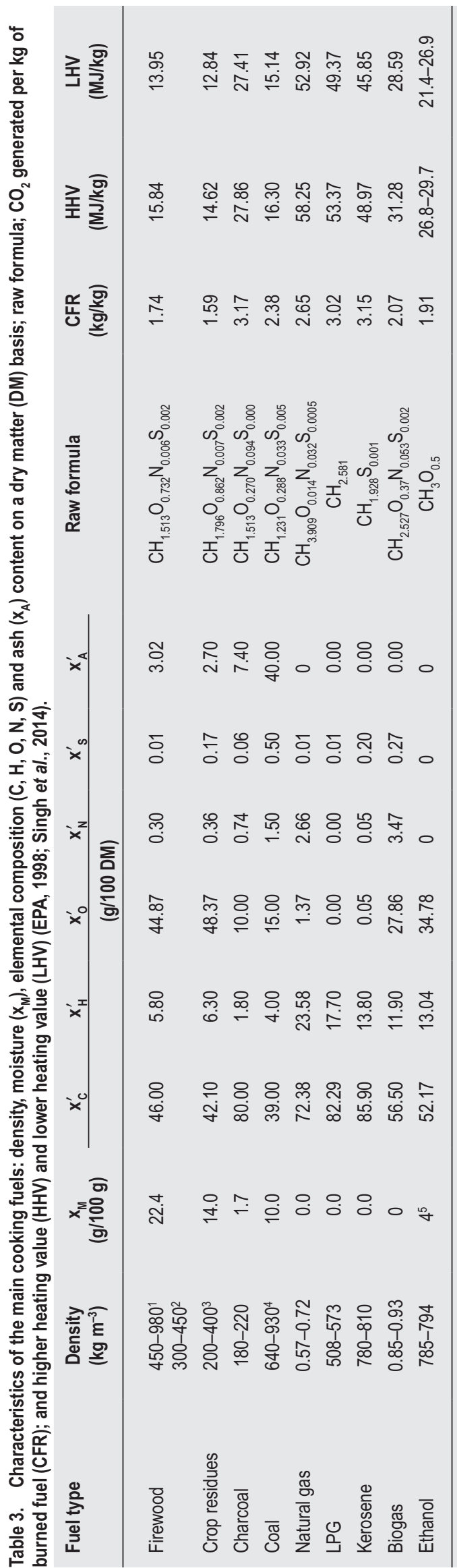

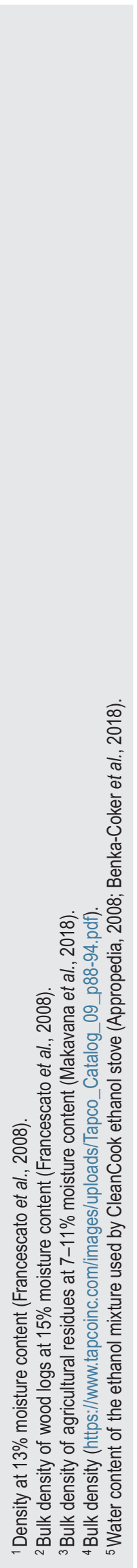


study on dry basis using one of the mathematical models available in literature (Vargas-Moreno et al., 2012). In this work, HHV and LHV (expressed in MJ/kg) were calculated as follows (Mukunda, 2009):

$$
\begin{gathered}
\mathrm{HHV}=33.823 \mathrm{x}_{\mathrm{C}}^{\prime}+144.249\left(\mathrm{x}_{\mathrm{H}}^{\prime}-\mathrm{x}_{\mathrm{O}}^{\prime} / 8\right)+9.418 \mathrm{x}_{\mathrm{S}}^{\prime}, \\
\mathrm{LHV}=\mathrm{HHV}-22.604 \mathrm{x}_{\mathrm{H}}^{\prime}-2.581 \mathrm{x}_{\mathrm{M}} .
\end{gathered}
$$

Table 3 shows the elemental composition and moisture content of typical firewood and crop residues (Singh et al., 2014), together with their estimated raw formula, theoretical amount of $\mathrm{CO}_{2}$ produced by the overall combustion of a unitary mass of biofuel, and higher and lower heating values calculated using Equations (1) and (2), respectively.

The heating value of anhydrous wood biomass varies between $18.5 \mathrm{MJ} / \mathrm{kg}$ and $19 \mathrm{MJ} / \mathrm{kg}$, whatever be the wood species examined. Owing to their higher lignin, resin, wax and oil contents, the heating value of conifers is about $2 \%$ higher than that of broad leave trees. The calorific value of anhydrous lignin $(26-27 \mathrm{MJ} / \mathrm{kg}$ ) is higher than that of cellulose $(17.2-17.5 \mathrm{MJ} / \mathrm{kg})$ or hemicellulose $(16 \mathrm{MJ} / \mathrm{kg})$. Further variability in the heating value is due to slight variation in hydrogen content and especially to diverseness in ash and moisture contents (Francescato et al., 2008).
Several crop residues (i.e., rice husk, wheat straw, cotton stalk, corn stover etc.), which are mostly left on fields after harvesting, and forestry residues (i.e., branches, leaves, bark etc.) are usually collected and burned by households. These are characterized by low bulk density and heating values in the range of $12-20 \mathrm{MJ} / \mathrm{kg}$, depending on their ash and moisture contents. Most of the woody biomass free from leaves and needles has an ash content of less than $2 \%$, while in some agricultural residues, it could be as high as $21 \%$ as in the case of rice husk (Shen et al., 2010).

Table 3 shows the ultimate composition of a typical mixture of crop residues used in India (Singh et al., 2014). Emissions in the air resulting from the combustion of typical firewood and crop residues as shown in Table 4 are derived from Singh et al. (2014). The resulting ash contents are generally disposed of in landfills. The theoretical $\mathrm{CO}_{2}$ emissions shown in Table 3 were greater than those obtained under conditions of real combustion, probably because of an inappropriate mass ratio of air to the solid fuel used.

\section{Charcoal}

Charcoal $(\mathrm{CHC})$ is a high-carbon solid fuel obtained from the carbonization of wood and wood wastes, which

\begin{tabular}{|c|c|c|c|c|c|c|c|c|}
\hline Emissions to air/waste & $\begin{array}{l}\text { Firewood } \\
(\mathrm{g} / \mathrm{kg})\end{array}$ & $\begin{array}{c}\text { Crop residues } \\
(\mathrm{g} / \mathrm{kg})\end{array}$ & $\begin{array}{c}\text { Charcoal } \\
(\mathrm{g} / \mathrm{kg})\end{array}$ & $\begin{array}{l}\text { Coal } \\
(\mathrm{g} / \mathrm{kg})\end{array}$ & $\begin{array}{c}\text { Natural gas } \\
\left(\mathrm{g} / \mathrm{STPm}^{3}\right)\end{array}$ & $\begin{array}{l}\text { Kerosene } \\
(\mathrm{g} / \mathrm{kg})\end{array}$ & $\begin{array}{l}\text { LPG } \\
(\mathrm{g} / \mathrm{kg})\end{array}$ & $\begin{array}{c}\text { Biogas } \\
(\mathrm{g} / \mathrm{kg})\end{array}$ \\
\hline $\mathrm{CO}_{2}$ (biogenic) & 326 & 1,302 & 625 & 0 & 0 & 0 & 0 & 1,450 \\
\hline $\mathrm{CO}_{2}$ & 1,032 & 0 & 1,979 & 1,559 & $1,918.5$ & 2,943 & 3,085 & 0 \\
\hline $\mathrm{CO}$ & 69 & 65.6 & 275 & 49 & 1.3 & 62 & 14.9 & 1.88 \\
\hline $\mathrm{CH}_{4}$ & 4.2 & 6.8 & 7.9 & 4.69 & 0.04 & 0.74 & 0.074 & 0.43 \\
\hline NO & 0.41 & 0.54 & 0.62 & 0.55 & 1.60 & 0.58 & 0.98 & 0.38 \\
\hline $\mathrm{NO}_{2}$ & 0.35 & 0.54 & 0.51 & 0.45 & 0.00 & 0.52 & 0.78 & 0.24 \\
\hline $\mathrm{N}_{2} \mathrm{O}$ & 0.09 & 0.05 & 0.08 & 0.08 & 0.04 & 0.09 & 0.015 & 0.009 \\
\hline $\begin{array}{l}\text { Non-methane volatile organic } \\
\text { compounds (NMVOC) }\end{array}$ & 7.35 & 8.2 & 10.3 & 10.5 & 0.09 & 13.2 & 10.59 & 0.56 \\
\hline $\mathrm{PM}_{2.5}$ & 3.3 & 7.5 & 0.4 & 12.2 & 0.12 & 1.9 & 0.32 & 0.66 \\
\hline $\mathrm{PM}_{10}$ & 4.34 & 7.54 & 0.43 & 17.9 & 0.00 & 0.52 & & 0.66 \\
\hline Total suspended particulate (TSP) & 1.04 & 0.63 & 2.19 & 1.3 & 0.00 & 0.7 & 0.51 & 0.52 \\
\hline Black carbon & 0.6 & 0.51 & 0.2 & 5.42 & 0.00 & 0.16 & 0.01 & 0.01 \\
\hline Organic carbon & 0.95 & 1.46 & 1.18 & 6.75 & 0.18 & 0.12 & 0.02 & 0.02 \\
\hline $\mathrm{SO}_{2}$ & 0.32 & 0.27 & 0.34 & 2.67 & 0.01 & 2.56 & 2.12 & 0.85 \\
\hline Formaldehyde & 0 & 0 & 0.03 & 0 & 0 & 0 & 0 & 0 \\
\hline Ash & 30.2 & 27 & 74 & 400.0 & 0 & 0 & 0 & 0 \\
\hline Digested slurry & 0 & 0 & 0 & 0 & 0 & 0 & 0 & 1060.0 \\
\hline
\end{tabular}

Table 4. Emissions to air and waste generated by the combustion of typical cooking fuels (EPA, 1998; Singh et al., 2014). 
are heated under limited aeration to remove water and volatile components. Such a process can be carried out in traditional earth mound kilns with a yield of about $14 \%$, or in closed retorts with yields as high as $25-40 \%$, thanks to the heat recovered from the combustion of volatile components baked off (Singh et al., 2014; Wikipedia, 2021d). Generally, the carbon content of charcoal ranges from 0.68 to $0.82 \mathrm{~kg}$ per kg of charcoal, which upon combustion gives rise to $2.5-3 \mathrm{~kg}$ of biogenic $\mathrm{CO}_{2}$ (Table 3). The main disadvantage of this process is the emission of unburnt methane, combustion gases, and particulates harmful to human health and the environment (Table 4).

\section{Coal}

Coal (CO) is a common resource of energy and chemicals. It is a complex heterogeneous solid composed of organic and inorganic matter with quite different chemico-physical properties. It is generally ranked on the basis of its carbon content into four types, namely, (1) anthracite with $86-97 \%$ carbon content $\left(\mathrm{x}_{\mathrm{C}}{ }_{\mathrm{C}}\right)$ and the highest heating value, (2) bituminous coal with $\mathrm{x}_{\mathrm{C}}=45-86 \%$, (3) sub-bituminous coal with $\mathrm{x}_{\mathrm{C}}{ }=35-45 \%$ and (4) lignite with $x_{C}^{\prime}=25-35 \%$. Table 3 shows the ultimate composition of a typical sub-bituminous coal generally used for cooking purposes. Its combustion gives rise to the emissions to air as listed in Table 4, and to coal ash usually disposed in landfills like that resulting from biomass fuels.

\section{Kerosene}

Kerosene (KER) is a combustible hydrocarbon liquid obtained from the fractional distillation of petroleum between $150{ }^{\circ} \mathrm{C}$ and $275^{\circ} \mathrm{C}$. It is mainly used as aviation fuel and indoor cooking fuel. Its typical physico-chemical properties are shown in Table 3, while main emissions after its combustion are shown in Table 4. Even in this case, the theoretical $\mathrm{CO}_{2}$ emissions (Table 3) were greater than those obtained under the real combustion conditions of this liquid fuel (Table 4).

\section{Natural Gas}

Natural gas is a nonrenewable mixture consisting of methane $(85-96 \% \mathrm{~mol} / \mathrm{mol})$, other alkanes $(1.9-7.4 \%$ $\mathrm{mol} / \mathrm{mol}$ ) and inert compounds (i.e., carbon dioxide, nitrogen and hydrogen sulfide) (Florida Power \& Light Co., 2003).

Table 3 shows typical properties and composition of NG. It is used as a fuel for generating electric and thermal energy, household heating and cooking, in vehicles as well as a chemical feedstock for manufacturing plastics and organic chemicals. It is primarily transported in its gaseous form using specific gas transmission network in industrialized countries. It can also be compressed and cooled into a liquid form and transported by sea. Emissions to the air resulting from its combustion are listed in Table 4 (US Environmental Protection Agency [EPA], 1998).

\section{Liquified Petroleum Gas}

Liquified petroleum gas is a fossil fuel mixture consisting of propane $\left(\mathrm{C}_{3} \mathrm{H}_{8}\right)$ and butane $\left(\mathrm{C}_{4} \mathrm{H}_{10}\right)$ with smaller percentage of isobutene and propylene. Its composition may range from $100 \%$ propane to $20 \%$ propane and $80 \%$ butane depending on the local winter and summer weather conditions, respectively. LPG can be manufactured during the refining of crude oil or extracted from petroleum or NG streams. It can be used as a fuel gas for heating and cooking, and in vehicles. To this end, it can be stored in portable steel cylinders, barbecue gas bottles and larger tanks. It is considered a clean cooking fuel because it gives rise to by far smaller indoor air pollution than biomass fuels. For this reason, LPG supply chains have been developed in several countries (e.g., Brazil, India, Indonesia, Bangladesh, Ethiopia, Haiti, Burundi, Mozambique etc.) to convert people in rural and urban areas to cleaner and healthier cooking solutions because its supply chain requires no investment in infrastructure as in the case of electricity grid and NG network (Rosenthal et al., 2018; Wright et al., 2020).

Table 3 shows the typical properties and composition of LPG, while Table 4 reports the main emissions to air as resulting from LPG cookstoves. Beyond the fact that LPG is ideal for users living in areas not accessible to NG lines, it has the advantage of a greater calorific value of 93.2 $\mathrm{MJ} / \mathrm{m}^{3}$ against $38.7 \mathrm{MJ} / \mathrm{m}^{3}$ for NG. Moreover, because of the easier regulation of mass ratio of air to LPG, the $\mathrm{CO}_{2}$ emitted during real burning is near to the theoretical amount shown in Table 3.

\section{Biogas}

Biogas (BG) is obtained from the process of anaerobic digestion of organic wastes, such as agricultural waste, manure, municipal waste, sewage, green waste and food waste, in anaerobic digesters (Bedoić et al., 2020). It mainly comprises methane $(50-75 \% \mathrm{v} / \mathrm{v})$, carbon dioxide $(25-45 \% \mathrm{v} / \mathrm{v})$ and nitrogen $(0-10 \% \mathrm{v} / \mathrm{v})$. It also contains small amounts of oxygen, ammonia, hydrogen and hydrogen sulfide, each being less than $1 \% \mathrm{v} / \mathrm{v}$, and siloxanes. Its moisture varies from $2 \% \mathrm{v} / \mathrm{v}$ at $20{ }^{\circ} \mathrm{C}$ to $7 \% \mathrm{v} / \mathrm{v}$ at $40{ }^{\circ} \mathrm{C}$. It is regarded as a renewable energy source, since its combustion practically releases the $\mathrm{CO}_{2}$ absorbed from 
the atmosphere in the growth of primary bio-resource. It can be used for different purposes, such as electricity and heat generation, cooking etc. A greater percentage of household-scale biogas digesters are installed in China and India. Economic governmental subsidies are provided to encourage rural population in Asia, Africa and South America to produce and use biogas at household levels, and thus avoid health problems associated with the use of biomass cookstoves (Wright et al., 2020).

Table 3 shows the typical properties and composition of biogas, while Table 4 reports the main emissions to air resulting from biogas cookstoves.

\section{Bioethanol}

Bioethanol is a renewable fuel used as a low-carbon alternative to fossil-derived fuels. It is the main fermentation product of yeast (e.g., Saccharomyces cerevisiae) or bacteria (e.g., Zymomonas mobilis) cultured on the media rich in simple sugars under anaerobic conditions. The so-called first-generation bioethanol stems from sugar-based raw materials (i.e., sugarcane, corn, sweet sorghum and cassava), while the second-generation bioethanol is derived from lignocellulose raw materials (such as straw, corn stover, wood trimmings, sawdust, bamboo, citrus peels etc.), which are presented for preliminary enzymatic treatment to hydrolyze cellulose (Kang et al., 2014). Brazil and the United States currently cover $\sim 85 \%$ of global supply of bioethanol by utilizing sugarcane and corn as substrates, respectively (Bertrand et al., 2016).

Numerous life cycle assessment studies attempted to estimate the environmental impact of bioethanol from different substrates with contradictory results. According to Jeswani et al. (2020), if no land-use change is involved, only bioethanol from sugarcane can meet the EU Renewable Energy Directive (EC, 2018a) of 60\% reduction in GHG emissions relative to petrol, while lignocellulosic bioethanol from agricultural and forest residues appears to have a greater mitigation effect. Among the several initiatives aiming at testing the use of ethanol cookstoves, it is worth citing the case of Gaia Association in Addis Ababa (Ethiopia), where the stoves are fed with 96\% (v/v) technical ethanol, which cannot be used as power ethanol for vehicles and is denatured with a bitter additive and dyed blue to make it unpalatable for drinking and unmistakable for water (Appropedia, 2008).

Table 3 shows the typical properties and composition of bioethanol. No information was found in the literature about the emissions in the air generated by ethanol cookstoves, although several studies monitored emissions to air resulting from the combustion of different ethanol-gasoline mixtures in spark-ignition engines (Iodice et al., 2018; Manzetti and Andersen, 2015). The ethanol blend of $85 \%(\mathrm{v} / \mathrm{v})$, generally used as a vehicle fuel in Brazil, generated 90\%, 15\% and 50\% less particulates, $\mathrm{CO}$ and $\mathrm{NO}_{\mathrm{X}}$, respectively, or benzene and 1,3-butadiene with respect to $100 \%$ gasoline, but almost 3.5 times higher carbonylic compound emissions were noted, mainly acetaldehyde (Costagliola et al., 2013).

\section{Electricity}

The use of electric energy (EL) for cooking results in no indoor emissions and smoke, and thus is a minimum health risk source. Nevertheless, such use affects ambient air pollution and climate change in a smaller or greater manner, especially if the electricity is made from wind turbines and solar photovoltaic panels or coal, respectively. Globally, about 26,603 TWh of electricity was generated in 2018 , about $38 \%$ of which being made from coal, $23 \%$ from NG, $10 \%$ from nuclear power plants and 25.5\% from renewables (International Energy Agency [IEA], 2019). In industrialized countries, where electrification rates are very high, about $50 \%$ and $61 \%$ of the cooking energy consumption in the EU-27 (Eurostat, 2021a) and the United States (IEA, 2018) is supplied by electricity whereas $31 \%$ and $33 \%$ by NG, respectively. Nevertheless, cooking devices consume about $6 \%$ of the overall energy consumption in the EU-27 and the US households, while the energy consumption for noncooking purposes (e.g., space and water heating, lighting and air conditioning) is by far dominating (Eurostat, 2021a). In low- and middleincome countries, use of electricity for cooking is limited, being even lower than the electricity access rate, for its high specific cost (Wright et al., 2020).

\section{Food Cooking Energy Requirements}

Several studies have attempted to measure the energy required to cook some food items in single or multiple portions using different cookstove or oven types, cooking fuels, and methods, and in some cases to assess the resulting GHG emissions (Carlsson-Kanyama and Boström-Carlsson, 2001; Foster et al., 2006; Frankowska et al., 2020; Martinez-Gómez et al., 2016; Nielsen, 2003). Many of these studies pointed out different thermal energy efficiencies of the main cooking systems used.

As an example, Table 5 shows the specific life cycle energy use (LCEU) and cooking time $\left(\mathrm{t}_{\mathrm{C}}\right)$ of a few food items as a function of different appliances and cooking modes, number of portions, including mass of food and water used, as interpreted by Carlsson-Kanyama and Boström-Carlsson (2001). For instance, these authors demonstrated that boiling water in an electric kettle or 
Table 5. Specific life cycle energy use (LCEU) and cooking time $\left(t_{c}\right)$ of a few food items as a function of different appliances and cooking modes used, number of portions, including the overall masses of food and water used (Carlsson-Kanyama and Boström-Carlsson, 2001).

\begin{tabular}{|c|c|c|c|c|c|c|c|}
\hline No. & Food Item & Appliance \& cooking mode & $\begin{array}{c}\text { No. of } \\
\text { portions }\end{array}$ & $\begin{array}{c}\text { Food mass } \\
(\mathrm{g})\end{array}$ & $\begin{array}{l}\text { Water mass } \\
\text { (g) }\end{array}$ & $\begin{array}{c}t_{c} \\
(\min )\end{array}$ & $\begin{array}{c}\text { LCEU } \\
\text { (MJ/kg) }\end{array}$ \\
\hline 1 & Wheat & Hotplate & 4 & 180 & 350 & 17 & 1.8 \\
\hline 2 & Wheat & Hotplate & 1 & 45 & 88 & 15 & 11.3 \\
\hline 3 & Wheat & Microwave oven & 4 & 180 & 350 & 15 & 2.1 \\
\hline 4 & Wheat & Microwave oven & 1 & 45 & 85 & 12 & 14.9 \\
\hline 5 & Barley & Hotplate & 4 & 160 & 700 & 23 & 2.3 \\
\hline 6 & Barley & Hotplate & 1 & 40 & 175 & 30 & 16.5 \\
\hline 7 & Barley & Microwave oven & 4 & 160 & 700 & 26 & 2.9 \\
\hline 8 & Barley & Microwave oven & 1 & 40 & 160 & 23 & 23.8 \\
\hline 9 & Couscous & Electric kettle & 4 & 240 & 300 & 1.00 & 4.0 \\
\hline 11 & Couscous & Hotplate & 4 & 240 & 300 & 2.42 & 4.2 \\
\hline 12 & Couscous & Hotplate & 1 & 80 & 100 & 2.00 & 13.8 \\
\hline 13 & Boiled potatoes & Hotplate & 4 & 800 & 1,000 & 32.4 & 1.1 \\
\hline 14 & Boiled potatoes & Hotplate & 1 & 190 & 600 & 28.3 & 6.8 \\
\hline 15 & Boiled potatoes & Hotplate ${ }^{1}$ & 4 & 800 & 1,000 & 32.4 & 1.1 \\
\hline 16 & Boiled potatoes & Hotplate $^{1}$ method & 1 & 190 & 600 & 28.3 & 6.3 \\
\hline 17 & Baked potatoes & Microwave oven & 4 & 1,200 & - & 28.0 & 1.2 \\
\hline 18 & Baked potatoes & Microwave oven & 1 & 300 & - & 7.0 & 5.0 \\
\hline 19 & Baked potatoes & Conventional oven & 4 & 1,200 & - & 65.0 & 1.8 \\
\hline 20 & Baked potatoes & Conventional oven & 1 & 300 & - & 65.0 & 20.0 \\
\hline 21 & Mashed potatoes & Electric kettle & 4 & 140 & 650 & 4.25 & 7.1 \\
\hline 22 & Mashed potatoes & Electric kettle & 1 & 35 & 175 & 2.25 & 28.6 \\
\hline 23 & Mashed potatoes & Hotplate & 4 & 140 & 650 & 1.83 & 7.9 \\
\hline 24 & Mashed potatoes & Hotplate & 1 & 35 & 175 & 0.83 & 34.3 \\
\hline 25 & Swedish-made pasta & Hotplate & 4 & 280 & 2,500 & 18 & 4.3 \\
\hline 26 & Italian-made pasta & Hotplate & 4 & 280 & 2,500 & 18 & 4.6 \\
\hline 27 & Swedish-made pasta & Hotplate & 1 & 70 & 1,000 & 14 & 21.4 \\
\hline 28 & Italian-made pasta & Microwave oven & 1 & 70 & 1,000 & 14 & 22.9 \\
\hline 29 & Fresh pasta & Microwave oven & 4 & 520 & 2,500 & 12 & 3.5 \\
\hline 30 & Fresh pasta & Microwave oven & 1 & 130 & 1,000 & 8 & 16.2 \\
\hline 31 & Rice & Hotplate & 4 & 240 & 600 & 20 & 4.2 \\
\hline 32 & Rice & Hotplate & 1 & 60 & 150 & 20 & 21.7 \\
\hline 33 & Rice & Microwave oven & 4 & 240 & 600 & 17 & 5.0 \\
\hline 34 & Rice & Microwave oven & 1 & 60 & 150 & 17 & 25.0 \\
\hline
\end{tabular}

${ }^{1}$ Energy-saving method.

baking a single portion of potatoes in a microwave oven was by far more energy-efficient than a hotplate or conventional oven. Moreover, Lakshmi et al. (2007) observed that an electric rice cooker was more energy-efficient than a pressure cooker or microwave cooker. Similarly, Martinez-Gómez et al. (2016) analyzed several cooking parameters for eight typical Ecuadorian meals when cooked using LPG-, coil- or induction-stoves. For example, the energy requirements to cook four hard-boiled eggs or grill $400-\mathrm{g}$ chicken reduced from about 0.44 to
0.29 or $0.2 \mathrm{kWh}$. This clearly indicated that induction stove was more efficient thermally than other stoves examined.

According to Frankowska et al. (2020), the cooking of vegetables (e.g., cabbage, carrots, cauliflower, onions and potatoes) and meat and fish accounts for around 61\% and $8-27 \%$ of total GHGs emitted during their overall life cycle, respectively. Similarly, home cooking of $1 \mathrm{~kg}$ of conventional dry pasta in $10 \mathrm{~L}$ of boiling water laced 
with $70 \mathrm{~g}$ of table salt consumed as much as $2.8 \mathrm{kWh} / \mathrm{kg}$, which represented about $50 \%$ of the cradle-to-grave carbon footprint, while wheat-milling and pasta-making and packaging or durum wheat cultivation covered $24.8 \%$ and $21.7 \%$ of total GHG emissions respectively (Cimini et al., 2020). By using the innovative Arduino-based eco-sustainable pasta cooker, operating with a water-to-dry pasta ratio of $3 \pm 1 \mathrm{~L} / \mathrm{kg}$ and consuming just $0.6 \pm 0.1 \mathrm{kWh} / \mathrm{kg}$ (Cimini et al., 2020), the cradle-to-grave carbon footprint of dry pasta reduced by $27 \%$ (Cimini et al., 2020). In the case of brewing of a cup of coffee using different coffee makers, the use phase represented the secondary hotspot (12.5-18.2\% of cradle-to-grave carbon footprint), coffee bean cultivation and green coffee production phase embodying $59-70 \%$ of total GHG emissions (Cibelli et al., 2021).

The cooking of lamb and beef is highly energy-intensive in consequences of their long cooking period ( $>1 \mathrm{~h}$ ) as in the case of roasting in an oven. Nevertheless, the contribution of their cooking to the total GHGs emitted was found to be lower than $10 \%$ because their cradle-to-grave carbon footprint was by far higher than that of vegetables. Under these circumstances, it would be much more environment-friendly to reduce the consumption of lamb and beef than to improve the energy efficiency of cooking method of choice (Frankowska et al., 2020).

Table 6 summarizes the specific energy requirements for cooking different food items using either a few ordinary moist (e.g., boiling, and frying), dry (grilling) and combined (microwave) heat cookery methods, as interpreted by Foster et al. (2006).

\section{Description of the Cooking Systems Studied}

A cooking system does not entail just the cookstove and oven but it accounts for the stove technology, cooking fuels and their supply chains, cookware, food materials as well as all the stages involved in the process of cooking from collection, handling, transportation and use of raw materials, extraction and/or refining, transportation to consumers, cooking, as well as post-consumer

Table 6. Specific energy requirements for cooking different food items using a few ordinary cookery methods (Foster et al., 2006).

\begin{tabular}{lc} 
Cookery methods & $\begin{array}{c}\text { Specific energy required } \\
\text { (MJ/kg of raw food) }\end{array}$ \\
\hline Boiling & 3.5 \\
Frying & 7.5 \\
Grilling & 8.5 \\
Microwave cooking & 0.34 \\
\hline
\end{tabular}

waste disposal. Its system boundary is sketched in Figure 1.

If the per capita cooking energy consumption per year is known as $\left(\mathrm{E}_{\mathrm{C}}\right)$, the mass of cooking fuels consumed $\left(\mathrm{m}_{\mathrm{CF}}\right)$ and the electric energy absorbed from the national grid $\left(\mathrm{E}_{\mathrm{EE}}\right)$ can be estimated as follows:

$$
\mathrm{m}_{\mathrm{CF}}=\frac{\mathrm{E}_{\mathrm{C}}}{\mathrm{LHV} \eta_{\mathrm{CS}}},
$$

and

$$
\mathrm{E}_{\mathrm{EE}}=\frac{\mathrm{E}_{\mathrm{C}}}{\eta_{\mathrm{CS}}\left(1-\eta_{\mathrm{EG}}\right)},
$$

where LHV is the lower heating value of each cooking fuel (see Table 3), $\eta_{\mathrm{CS}}$ is the average thermal efficiency of cookstove, and $\eta_{\mathrm{EG}}$ is the average loss of electric grid. While the range of values for $\eta_{\mathrm{CS}}$ is shown in Table 2 , the latter was about $5.8 \%$ for the Italian grid in 2020 (Terna, 2020).

Specific emissions into the air, water and solid wastes resulting from the use of different cooking fuels are reported in Table 4. In Italy, electricity is produced mainly from fossil fuels (52\% of total, that is, $43 \%$ from NG, $4.3 \%$ from coal and $1.0 \%$ from petroleum products etc.), and from renewable energy sources (37.6\% of total, that is, $15.3 \%$ from hydroelectric sources, $8.3 \%$ from solar, $6.0 \%$ from wind and $1.94 \%$ from geothermic power, and $6.3 \%$ from biofuels) (Terna, 2020).

\section{Methodology}

The life-cycle analysis (LCA) was carried out according to specific international standards (International

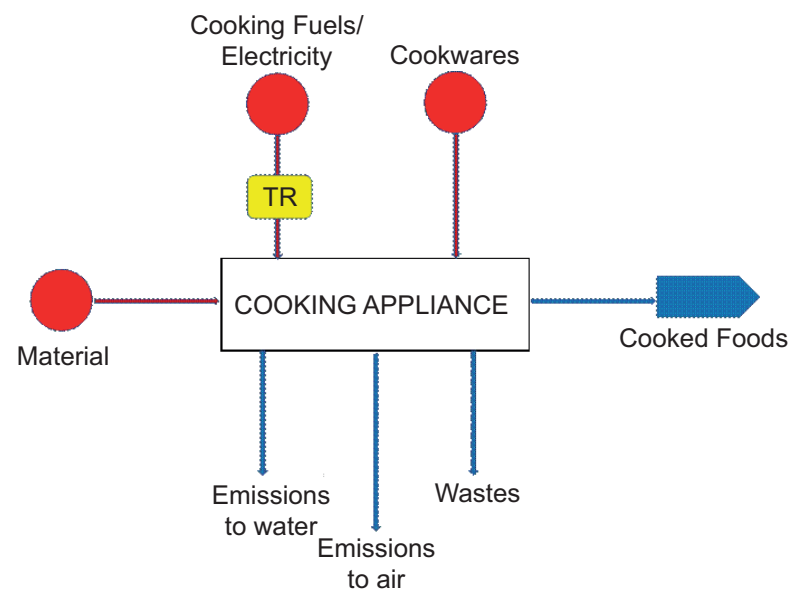

Figure 1. Schematic of a generic cooking system, including the transportation stage (TR) of cooking fuels. 
Organization for Standardization [ISO], 2006a, 2006b), and included the following stages: Goal and scope definition, inventory analysis, impact assessment and interpretation of results.

\section{Goal and scope definition}

The goal of this study was to determine the potential life cycle environmental impacts of different cooking fuels (i.e., firewood, charcoal, kerosene, NG, LPG, biogas and electricity) in Italy using the LCA software Simapro 9.2.0.2 (Prè Consultants, Amersfoort, NL) with embedded background Ecoinvent v. 3.7 database. The cooking energy requirements depend not only on the thermal efficiency $\left(\eta_{\mathrm{CS}}\right)$ of the cookstove used but also on the type and energy (LHV) value of each fuel, as shown in Tables 2 and 3. For a valid comparison between different cooking systems, the production of useful EU-27 per capita cooking energy consumption of $1.41 \mathrm{GJ} / \mathrm{yr}$, as transferred to the cooking pot after the combustion of each fuel in the cookstove, was used as the functional unit. In this way, differences in the fuel energy values and efficiencies of end-use cookstoves were accounted for.

As suggested by the guidelines established by the Publicly Available Specification (PAS) 2050 standard method (British Standards Institution [BSI], 2011), the production of capital goods (cookstoves, cookware etc.) as well as their cleaning and disposal (Section 6.4.4; BSI, 2011), was not included in the system boundary. Such assumption was also corroborated by a few LCA analyses which confirmed that the use phase was responsible for the greatest environmental impact in several impact categories in the case of mud stoves for firewood (Afrane and Ntiamoah, 2012), gas and induction hobs (Favi et al., 2018), electric and gas ovens (Landi et al., 2019) as well as domestic induction hobs equipped with different electronic boards (Elduque et al., 2014). Additionally, the lifespan of each cookstove was, in general, more than 10 years, this being the average life of the appliances installed in Italy (Favi et al., 2018). In addition, the production and transportation of food materials, as well as the transportation and disposal of food wastes, were excluded from the system boundaries, as they were assumed to be the same for all the cookstoves examined.

\section{Inventory analysis}

The production processes of all cooking fuels, as well as electricity drawn from the Italian grid mix, were extracted from the Ecoinvent v. 3.7 database (Table 7).
Solid (i.e., firewood, charcoal and coal) and liquid (i.e., kerosene and LPG) cooking fuels were distributed by road using Euro5 lorries with a load capacity of 3.5-7.5 $\mathrm{Mg}$ for an average distance of $50 \mathrm{~km}$. Kerosene was packed in 20-L high-density polyethylene tanks weighing $0.75 \mathrm{~kg}$ each and LPG was filled into $10-\mathrm{kg}$ steel bottles, weighing $11 \mathrm{~kg}$ each. Finally, gaseous fuels (i.e., NG and biogas) were distributed by $50-\mathrm{km}$ pipelines, while electricity was drawn from the Italian grid mix.

Pollutants from cookstoves are mainly derived from incomplete combustion processes. They included biogenic and/or fossil $\mathrm{CO}_{2}$, carbon monoxide, methane, oxides of nitrogen $\left(\mathrm{NO}_{\mathrm{X}}\right)$, non-methane volatile organic compounds (NMVOC), particulate matter (PM), black carbon, organic carbon compounds and sulfur dioxide. These pollutants are of great concern because of their harmful effects on human health. Electric cookstoves have no direct indoor emissions but a more or less severe indirect environmental impact depending on the electric power supply.

Emissions and solid wastes resulting from the combustion of fuels (Singh et al., 2014) are shown in Table 4, as referred to $1 \mathrm{~kg}$ of cooking fuel or 1 standard temperature and pressure (STP) $\mathrm{m}^{3}$ of NG. The effective mass of cooking fuels burnt and electricity drawn from the electric grid were calculated by using Equations (3) and (4), respectively.

Finally, solid wastes (wood and coal ash) from cookstoves were disposed of in landfills.

\section{Impact assessment}

The impact assessment was carried out using the ReCiPe 2016 (Huijbregts et al., 2016), and PEF (EC, 2018b; Manfredi et al., 2012; Sala et al., 2017, 2018) standard methods, all these methods being embedded in the software SimaPro 9.2.0.2.

Any generic impact category $\left(\mathrm{IC}_{\mathrm{j}}\right)$ was estimated by summing up release into the air, water and soil ( $\psi_{\mathrm{i}}$, expressed in mass, energy, and mass-km basis) associated to the system boundaries times its corresponding characterization factor $\left(\mathrm{F}_{\mathrm{i}, \mathrm{j}}\right)$ as:

$$
\mathrm{IC}=\sum_{\mathrm{i}}\left(\Psi_{\mathrm{i}, \mathrm{j}} \mathrm{F}_{\mathrm{i}, \mathrm{j}}\right)
$$

The updated ReCiPe 2016 method (Huijbregts et al., 2016) included the following 18 midpoint impact categories; the reference substance of each is indicated in parentheses: global warming $\left(\mathrm{kg} \mathrm{CO}_{2 \mathrm{e}}\right)$; stratospheric 
Table 7. Production processes for the cooking fuels used in this work (extracted from the Ecoinvent v. 3.7 database).

Cooking fuels Ecoinvent v. 3.7 database Description
$\begin{array}{ll}\text { Firewood } & \text { Wood pellet, measured } \\ & \text { as dry mass (RoW)| wood }\end{array}$ pellet production| cut-off, $S$

Charcoal

Charcoal (GLO)| production| cut-off, $S$

Coal Hard coal (Europe, without Russia and Turkey)| market for hard coall cut-off, $S$

Natural gas Natural gas, high pressure (IT)| import from RU| cut-off, S

Electricity, low voltage (IT)| market for| cut-off, S

Electricity, low voltage (FR)| market for| cut-off, S

Electricity, low voltage (PL)| market for| cut-off, S

gas (Europe without Switzerland)| liquefied petroleum refinery operation| cut-off, S Switzerland) | kerosene production, petroleum refinery operation| cut-off, $S$

Biogas (RoW)| anaerobic digestion of manure| cut-off, $S$

Wood pellets are produced in a wood pellets factory, which uses wood residue from sawmills and woodchips as raw materials. The raw materials are first pre-treated and dried; then comminuted, mixed, pelletized, cooled and bagged. $20 \%$ of the production was packed in $15-\mathrm{kg}$ bags, while the remaining $80 \%$ was sold unpacked.

Charcoal with an average carbon content of $80 \%(\mathrm{w} / \mathrm{w})$ is produced from hardwood from forest plantations.

This activity starts at the hard coal preparation plant with coal ready to be loaded on rail, truck, barge or conveyor. The activity ends with the unloading of hard coal at domestic consumers or export hubs. The inventory refers to the average transport distance specific to the domestic market of hard coal in Europe without Russia and Turkey.

This dataset represents the extraction of NG in the Russian Federation and includes the following activities: exploration, production, processing, underground storage of NG, and feeding of produced gas in the pipeline for transport to the country where it is consumed. The leakages of production and processing of the raw gas are included.

This dataset describes the transport required for the export of Russian NG to Italy (expressed in $\mathrm{Mg} \mathrm{km}$ ). Gas losses and emissions during seasonal storage are included. An average distance of $6,400 \mathrm{~km}$ is estimated for the export. includes electricity inputs produced in France from imports and transformed to low voltage, the transmission network, direct emissions to air $\left(\mathrm{SF}_{6}\right.$ from the insulation gas in the high-voltage level switchgear are allocated to the electricity demand on medium voltage), and electricity losses during transmission. This dataset excludes electricity losses during transformation from high to medium voltage or medium to low, as these are included in the dataset for transformation, leakage of insulation oil from cables and electro technical equipment, $\mathrm{SF}_{6}$ emissions during production and deconstruction of the switchgear, as these are accounted for in the transmission network dataset.

This dataset describes the electricity available on low-voltage level in Poland in 2017. It includes electricity inputs produced in Poland and from imports and transformed to low voltage, the transmission network, direct emissions to air $\mathrm{SF}_{6}$ from the insulation gas in the high-voltage level switchgear are allocated to the electricity demand on medium voltage level), electricity losses during transmission. This dataset excludes electricity losses during transformation from high to medium voltage or medium to low, as these are included in the dataset for transformation, leakage of insulation oil from cables and electro technical equipment (transformers, switchgear and circuit breakers) because this only happens in case of accidental release, $\mathrm{SF}_{6}$ emissions during production and deconstruction of the switchgear, as these are accounted for in the transmission network dataset. 
Table 7. Continued

\begin{tabular}{|c|c|c|}
\hline Cooking fuels & Ecoinvent v. 3.7 database & Description \\
\hline & $\begin{array}{l}\text { Electricity, high-voltage } \\
\text { (IT)| electricity production, } \\
\text { hydro, reservoir, alpine } \\
\text { region| cut-off, S }\end{array}$ & $\begin{array}{l}\text { This dataset represents the production of high-voltage electricity at grid-connected reservoir } \\
\text { hydropower plants in Italy in } 2012 \text {. Net average electrical efficiency, including pipe losses, is } \\
78 \% \text {. This dataset starts from the power plant ready to produce electricity, i.e., the reservoir } \\
\text { filled with water, and ends with } 1 \mathrm{kWh} \text { of high-voltage electricity produced at the power plant and } \\
\text { arrived at the busbar. This dataset doesn't include land use for access roads to the reservoir, } \\
\text { emissions of carbon dioxide, raw materials extraction, decommissioning and waste treatment } \\
\text { as these activities are already included in the infrastructure datasets, transformation of the } \\
\text { electricity produced. }\end{array}$ \\
\hline & $\begin{array}{l}\text { Electricity, high-voltage } \\
\text { (IT)| electricity production, } \\
\text { wind, 1-3-MW turbine, } \\
\text { onshore| cut-off, S }\end{array}$ & $\begin{array}{l}\text { This dataset represents the production of high-voltage electricity at on-shore grid-connected } \\
\text { wind power plants with a capacity between } 1 \mathrm{MW} \text { and } 3 \mathrm{MW} \text { in Italy in 2005-2020. It includes } \\
\text { operation and maintenance expenditures as well as infrastructure inputs. }\end{array}$ \\
\hline & $\begin{array}{l}\text { Electricity, low-voltage } \\
\text { (IT)| electricity production, } \\
\text { photovoltaic, 570-kWp } \\
\text { open ground installation, } \\
\text { multi-Si | cut-off, S }\end{array}$ & $\begin{array}{l}\text { This dataset represents the production of grid-connected low-voltage electricity with a } 570-\mathrm{kWp} \\
\text { open ground photovoltaic plant in Italy in 2008-2020. An inverter is used to convert the low- } \\
\text { voltage DC power into AC power. Use of tap water for cleaning the module and its treatment is } \\
\text { included. }\end{array}$ \\
\hline
\end{tabular}

ozone depletion ( $\mathrm{kg}$ trichlorofluoromethane or freon11, CFC-1 $\left.11_{\mathrm{e}}\right)$; ionizing radiation $\left(\mathrm{kBq}{ }^{60} \mathrm{Co}_{\mathrm{e}}\right)$; fine PM formation $\left(\mathrm{kg} \mathrm{PM}_{2.5 \mathrm{e}}\right)$; ozone formation-human health, and ozone formation-terrestrial ecosystems ( $\mathrm{kg} \mathrm{NO}$ xe); terrestrial acidification $\left(\mathrm{kg} \mathrm{SO}_{2 \mathrm{e}}\right)$; freshwater $\left(\mathrm{kg} \mathrm{P}_{\mathrm{e}}\right)$ and marine $\left(\mathrm{kg} \mathrm{N} \mathrm{N}_{\mathrm{e}}\right)$ eutrophication; terrestrial, freshwater, and marine ecotoxicity ( $\mathrm{kg}$ 1,4-Dichlorobenzene [DCB]); human carcinogenic and noncarcinogenic toxicity $(\mathrm{kg}$ 1,4-DCB); land use ( $\mathrm{m}^{2}$ annual crop $\left.\mathrm{e}\right)$; mineral $(\mathrm{kg} \mathrm{Cu})$

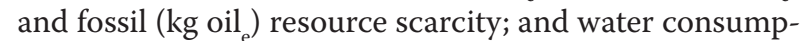
tion $\left(\mathrm{m}^{3}\right)$. Finally, the PEF method accounted for the following 16 impact categories, the reference substance of each is indicated in parentheses: climate change $(\mathrm{kg}$ $\mathrm{CO}_{2 \mathrm{e}}$ ), ozone depletion ( $\mathrm{kg} \mathrm{CFC}-11_{\mathrm{e}}$ ), ionizing radiation-human health $\left(\mathrm{kBq}^{235} \mathrm{U}_{\mathrm{e}}\right)$, photochemical ozone formation (kg NMVOC ), PM (diseases included), human toxicity, noncancer (Human Comparative Toxic Unit, $\mathrm{CTU}_{\mathrm{h}}$ ); human toxicity, cancer $\left(\mathrm{CTU}_{\mathrm{h}}\right)$, acidification (mol $\mathrm{H}_{\mathrm{e}}^{+}$), freshwater eutrophication ( $\mathrm{kg} \mathrm{P}_{\mathrm{e}}$ ), marine eutrophication $\left(\mathrm{kg} \mathrm{N}_{\mathrm{e}}\right)$; terrestrial eutrophication $\left(\mathrm{mol} \mathrm{N}_{\mathrm{e}}\right)$, freshwater ecotoxicity (ecotoxicity Comparative Toxic Unit, $\mathrm{CTU}_{\mathrm{e}}$ ), land use (point $\left.[\mathrm{Pt}]\right)$, water scarcity ( $\mathrm{m}^{3}$ depriv.), resource use-fossils $(\mathrm{MJ})$, and resource use-mineral and metals $\left(\mathrm{kg} \mathrm{Sb}_{\mathrm{e}}\right)$.

Both standard methods combine the above-mentioned environmental impacts into one point value. More specifically, the ReCiPe 2016 method groups the aforementioned impact categories into the following three endpoint indicators: (i) damage to human health $(\mathrm{HH})$, expressed in DALY, that is, the number of years of life lost as a result of premature mortality and/or disability after an exposure to toxic chemicals; (ii) damage to ecosystem quality (EQ), expressed in loss of species during a year; and (iii) damage to resource availability (RA), expressed in US\$ 2013 to quantify the extra costs involved for future mineral and fossil resource extraction. Such damage categories are then normalized with respect to the global population and aggregated using specific weights. Finally, the three damage categories may be grouped into individualistic, hierarchic, or egalitarian perspective, according to the 'Cultural Theory' (Thompson et al., 1990). In this study, hierarchic perspective was used to estimate the overall weighted damage score $\left(\mathrm{OWDS}_{\mathrm{R}}\right)$, since such a perspective is regarded as the most balanced one between future and present impacts, and risks and benefits (Huijbregts et al., 2016). Thus, the midpoint ReCiPe-Hierarchic $(\mathrm{H})$ version-Europe was used to characterize the results of LCIA, while the environmental impacts were calculated according to the ReCiPe endpoint - Hierarchic $(\mathrm{H})$ version-Europe H/A - with the average weighting set (A), both methods being encoded in the LCA software SimaPro 9.2.0.2.

Concerning the PEF method, any impact category was normalized with respect to its corresponding global impact as recommended by Sala et al. (2017), weighted as suggested by Sala et al. (2018), and finally summed up to yield another overall weighted score $\left(\mathrm{OWS}_{\mathrm{p}}\right)$.

\section{Sensitivity analysis}

Uncertainty in the outputs of the above-mentioned LCA models was mainly apportioned to the range of variations in thermal efficiency $\left(\eta_{\mathrm{CS}}\right)$ of the cooking fuels used (see Table 2) and to the electric power supply (i.e., the French or Polish grid mix, hydro, solar photovoltaic and 
wind power). In particular, the French electricity mix is largely dominated by the nuclear power, while coal governs the power sector of Poland (www.iea.org/countries). Once the default triangular and/or normal distribution uncertainty range for $\eta_{\mathrm{CS}}$ was accounted for, it was possible to resort to the well-known Monte Carlo analysis (Theodoridis, 2015).

\section{Results and Discussion}

\section{Mid-point environmental profile of the cooking systems examined}

Environmental impacts of the cooking fuels examined in this work at the first stage of cause-effect chain are shown in Table 8, depicted according to the ReCiPe 2016 and PEF standard methods.

According to the ReCiPe 2016 method, the use of coal appeared to have the maximum impact in 12 of the 18 categories (i.e., global warming, fine PM formation, ozone formation affecting human health and terrestrial ecosystems, terrestrial acidification, freshwater and marine eutrophication and ecotoxicity, human carcinogenic and noncarcinogenic toxicity, and fossil resource scarcity). The use of charcoal, electricity and firewood largely affected three impact categories (namely, stratospheric ozone depletion, land use and water consumption), two impact categories (e.g., ionizing radiation and mineral resource scarcity), and one (terrestrial ecotoxicity) impact category, respectively. In contrast, the use of NG gave rise to the minimum impact in 9 of the 18 categories (i.e., ionizing radiation, fine PM formation, terrestrial acidification, freshwater eutrophication, terrestrial, freshwater and marine ecotoxicity, human noncarcinogenic toxicity, and land use). The use of biogas, LPG and kerosene minimized the impact of four impact categories (i.e., global warming, ozone formation affecting human health and terrestrial ecosystems, and fossil resource scarcity), four impact categories (namely, stratospheric ozone depletion, marine eutrophication, human carcinogenic toxicity, and mineral resource scarcity) and one impact category (water consumption), respectively.

In addition, with the PEF method, the use of coal appeared to have the maximum impact in 10 of the 16 categories (i.e., climate change, photochemical ozone formation, PM, acidification, freshwater, marine and terrestrial eutrophication, freshwater ecotoxicity, resource use, that is, fossils and mineral and metals). The use of charcoal, NG and electricity had the maximum impact on four impact categories (namely, human noncancer and cancer toxicity, land use, and water scarcity), one impact category (ozone depletion), and one impact category (ionizing radiation), respectively. In agreement with the other LCIA method, the use of NG led to minimum impact in 10 of the 16 categories (i.e., ionizing radiation, photochemical ozone formation, PM, noncancer and cancer human toxicity, acidification, eutrophication freshwater, ecotoxicity freshwater, land use, and resource use, that is, -mineral and metals). The use of kerosene and biogas exerted minimum impact on the remaining three (i.e., marine, terrestrial eutrophication, and water scarcity) and three (namely, climate change, ozone depletion, and resource use, that is, fossils) impact categories, respectively.

Whereas the PEF method refers to the 100-year time horizon global warming potentials (Myhre et al., 2013), in the ReCiPe 2016 method, the characterization factors for global warming differ from the former because climate-carbon feedback for non- $\mathrm{CO}_{2}$ GHGs is included (Huijbregts et al., 2017). Therefore, scores of the global warming category, as estimated using both methods, resulted to be slightly different. These ranged from as high as $1,210 \mathrm{~kg} \mathrm{CO}_{2 \mathrm{e}}$ in the case of coal cookstoves to as low as $153 \mathrm{~kg} \mathrm{CO}_{2 \mathrm{e}}$ in the case of biogas cookstoves. Except for charcoal cookstoves (which emitted about 607 $\mathrm{kg} \mathrm{CO}_{2 \mathrm{e}}$ ), all other cookstoves emitted 188-256 $\mathrm{kg} \mathrm{CO}_{2 \mathrm{e}}$ per person per year. By contrast, thanks to the model developed by van Zelm et al. (2016), it was possible to assess maximum formation of fine PM if using coal, firewood and charcoal cookstoves (i.e., 7.5, 2.3 and $0.46 \mathrm{~kg}$ $\mathrm{PM}_{2.5 \mathrm{e}}$ per person per year, respectively), and minimum formation of fine PM if using NG cookstoves $(\sim 0.1-\mathrm{kg}$ $\mathrm{PM}_{2.5 \mathrm{e}}$ ). LPG and kerosene cookstoves emitted about $0.15-0.27 \mathrm{~kg} \mathrm{PM}_{2.5 \mathrm{e}}$ per person per year. These results were similar to those obtained with the PEF method, despite this method estimates the impact of such a category in terms of disease incidence using the United Nation Environment Program (UNEP) model (Fantke et al., 2016).

\section{End-point environmental profile of the cooking systems examined}

The ReCiPe 2016 standard method groups its 18 midpoint impact categories into three damage categories (DC) to highlight the environmental compartments damaged by any cooking system during its life cycle. In particular, the impact categories of global warming and water consumption exerted their damage to both human health and ecosystem quality compartments. By contrast, the categories of stratospheric ozone depletion, ionizing radiation, fine PM and ozone formation affecting human health, and human carcinogenic and noncarcinogenic toxicity affected the human health compartment only, while categories of ozone formation affecting terrestrial ecosystems, terrestrial acidification, freshwater and marine eutrophication, terrestrial, freshwater and marine 


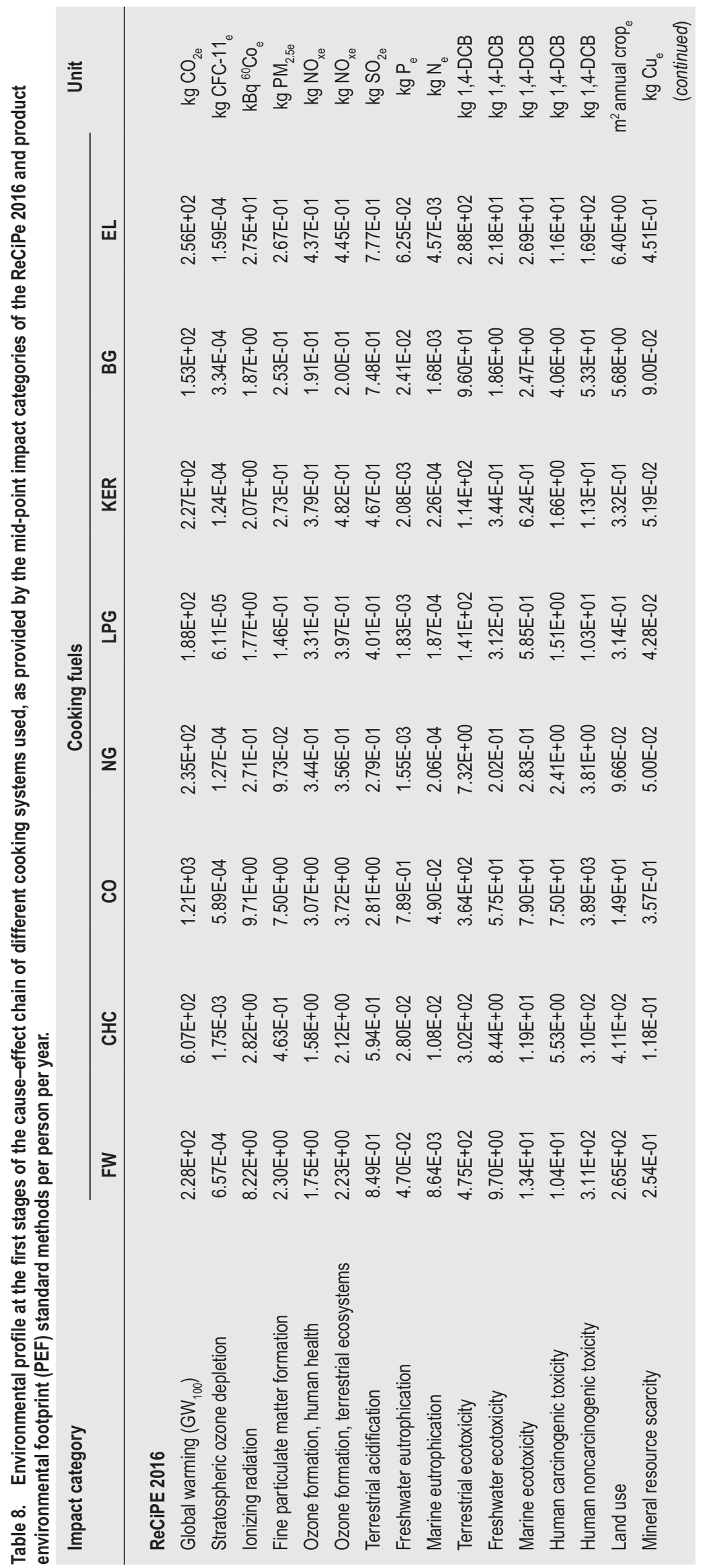




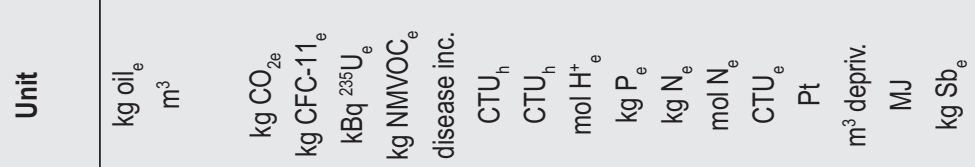

후윟 웅

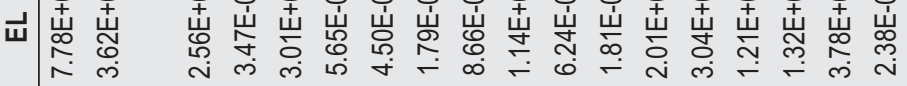

ट

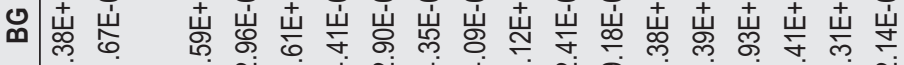

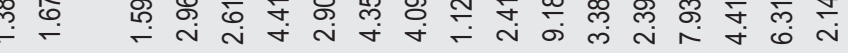

중 శ్ర

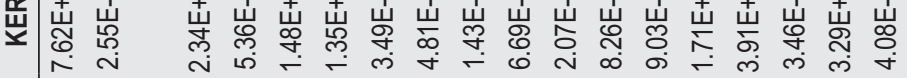

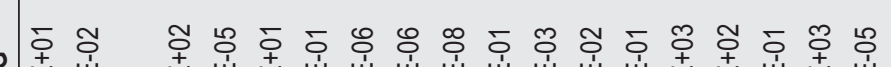

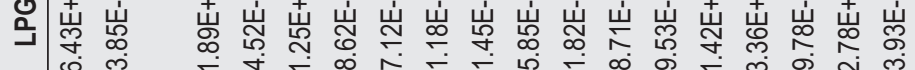

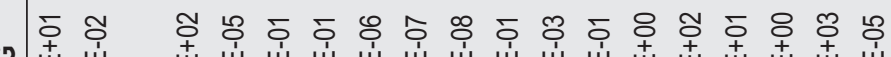

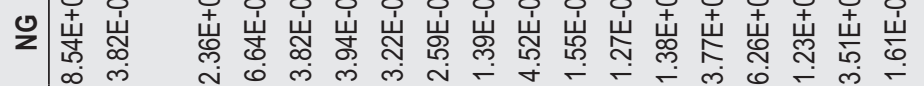

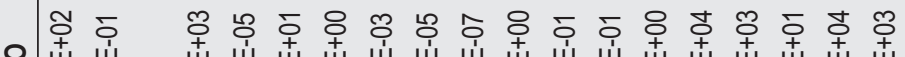

ᄋ m $\infty$ ஸ़

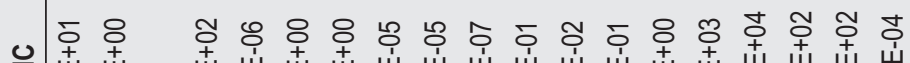

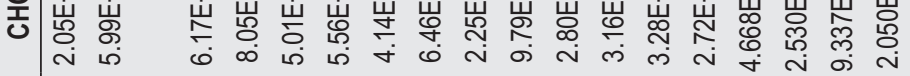

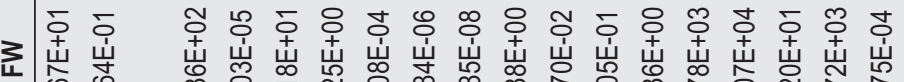
๗ீ

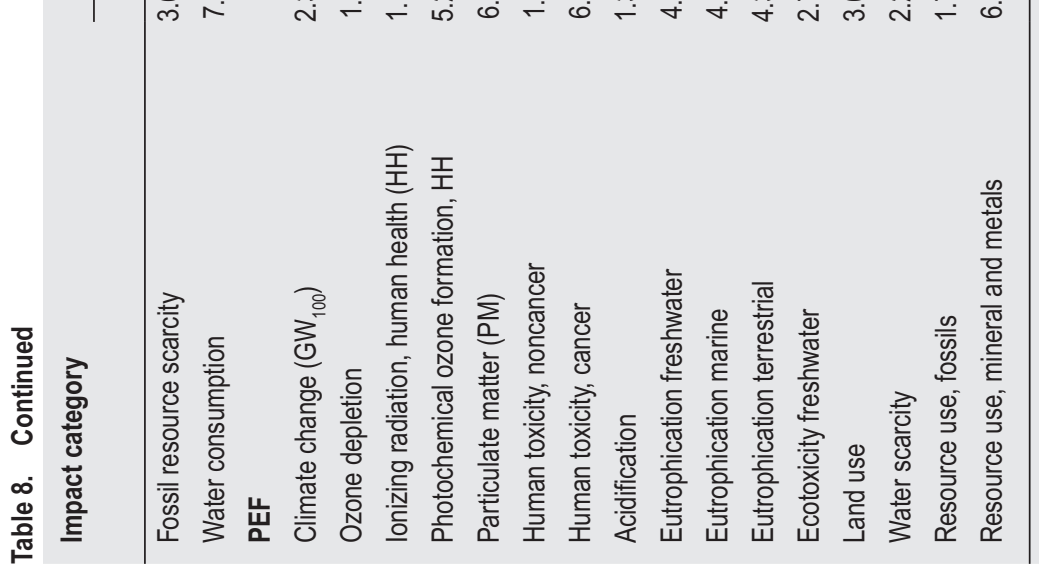


ecotoxicity, and especially land use distressed the ecosystem quality compartment. Finally, the categories of mineral and fossil resource scarcities limited the resource availability compartment.

Table 9 shows single scores of the three damage categories for any cooking system examined, which were first normalized and then aggregated to complete assessment to the end-point approach.

The use of coal appeared to have maximum impact on two of the three damage categories (i.e., human health and resource availability). The use of charcoal affected maximum the other damage category (ecosystem quality). In contrast, the use of NG exerted the least impact on human health and ecosystem quality, while the use of biogas had a minimum impact on resource availability. The resulting single score $\left(\mathrm{OWDS}_{\mathrm{R}}\right)$ was maximum in the case of coal cookstoves $(118 \mathrm{Pt})$ and minimum in the case of LPG cookstoves ( 5 Pt). The contribution of damage to human health ranged from $91 \%$ to $98 \%$ of OWDS R $_{R}$ the case of charcoal and coal cookstoves, respectively. Moreover, the overall weighted damage score for NG, biogas, kerosene and electricity cookstoves were 5.2, 5.7, 7.0 and $8.6 \mathrm{Pt}$, respectively; these scores confirmed their suitability for being included in the category of the so-called clean cooking fuels (IEA and the World Bank, 2014).

As suggested by the PEF method, all mid-point impact categories were normalized with respect to their corresponding global impact and weighted to obtain another single score $\left(\mathrm{OWS}_{\mathrm{p}}\right)$. Even with this method, the overall environmental impact of coal cookstoves was maximum (425 millipoint [mPt]), while that of LPG cookstoves was minimum $(12.6 \mathrm{mPt})$. Higher scores characterized the NG (12.9 mPt), biogas $(14.2 \mathrm{mPt})$, kerosene $(19.7 \mathrm{mPt})$ and electricity $(21.8 \mathrm{mPt}$ ) cookstoves, while the overall environmental impact of firewood and charcoal cookstoves represented just $27 \%$ and $11 \%$ of OWS of coal cookstoves (Table 9). It also confirmed the predominant contribution of PM on $\mathrm{OWS}_{\mathrm{P}}$ for coal (75\%) and firewood (79\%) cookstoves; it was minimum in the case of electric (3\%) and NG (4\%) cookstoves. It is worth pointing out that such a contribution grew to $13 \%, 27 \%$ and $31 \%$ in the case of charcoal, kerosene and biogas cookstoves (Table 9).

\section{Sensitivity analysis}

Figure 2 shows how the environmental single scores, $\mathrm{OWDS}_{\mathrm{R}}$ and $\mathrm{OWS}_{\mathrm{p}}$, of cooking systems under study were affected by uncertainty of thermal efficiency $\left(\eta_{\mathrm{CS}}\right)$ of the cooktops used (Table 2). Such mean values were derived from the Monte Carlo analysis (using a fixed number of 2,000 runs) and characterized by standard deviations ranging from $\sim 3 \%$ (in the case of biogas cookstove) to $19 \%$ (in the case of charcoal cookstove). Moreover, at a probability level of 0.05 , there was no statistically significant difference between the overall scores for NG and LPG cookstoves. Under these circumstances, both cooking fuels appeared to be less damaging to the compartments of human health and ecosystem quality, and thus more apt to minimize both indoor and outdoor air

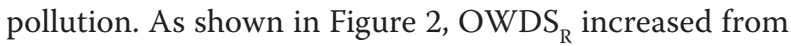
a minimum value of $\sim 5 \mathrm{Pt}$ to $6 \mathrm{Pt}, 7 \mathrm{Pt}$ and $9 \mathrm{Pt}$ if biogas, kerosene and electric cookstoves are used, respectively. Quite similar results were obtained by comparing the overall weighted scores $\mathrm{OWS}_{\mathrm{p}}$ according to the PEF method (Figure 2).

In the case of electric cookstoves, both single scores were related to different primary energy sources producing electricity in Italy. To point out the effect of different nonrenewable and/or renewable sources used to generate electricity, it was assumed to draw electricity from the French and Polish grid mix, or from hydro, solar photovoltaic and wind power plants. Table 10 shows the mean values and standard deviations for damage categories of human health, ecosystem quality and resource availability, as such or normalized, as well as the overall weighted score OWDS $\mathrm{R}_{\mathrm{R}}$ and OWS for the electric cooking system examined.

If using the Italian grid mix, which uses about $52 \%$ fossil sources (mainly NG) and 37.6\% renewable ones (mainly hydroelectric and wind power) (Terna, 2020), OWDS $\mathrm{R}_{\mathrm{R}}$ was equal to about $8.7 \mathrm{Pt}$ and was practically controlled by damage to ecosystem quality. By contrast, large use of electricity from nuclear power in France had positive effects of reducing OWDS ${ }_{R}$ to about one-third $(3.1 \mathrm{Pt})$; however, this being predominantly affected by damage to human health. Such a damage enhanced up to 28.8 Pt when using the electricity produced by coal power plants as in Poland, while the total environmental score OWDS $_{R}$ amounted to $\sim 30 \mathrm{Pt}$ (Table 10). By using renewable energy sources only, $\mathrm{OWDS}_{\mathrm{R}}$ reduced to as low as $\sim 0.9$ Pt if hydropower electricity was used. It slightly increased to 1.4 and $2.8 \mathrm{Pt}$ if electricity was generated through wind and solar photovoltaic plants, respectively (Table 10).

According to the PEF method, the single environmental score $\mathrm{OWS}_{\mathrm{p}}$ was maximum in the case of Polish grid mix $(59 \mathrm{mPt})$ but almost indifferent in the case of Italian and French grid mix (21-22 mPt). It reached a minimum value if electricity from wind was used $(1.8 \mathrm{mPt})$ but increased to $6.3 \mathrm{mPt}$ and $8.4 \mathrm{mPt}$ if electricity was used from hydropower and solar energy, respectively. 


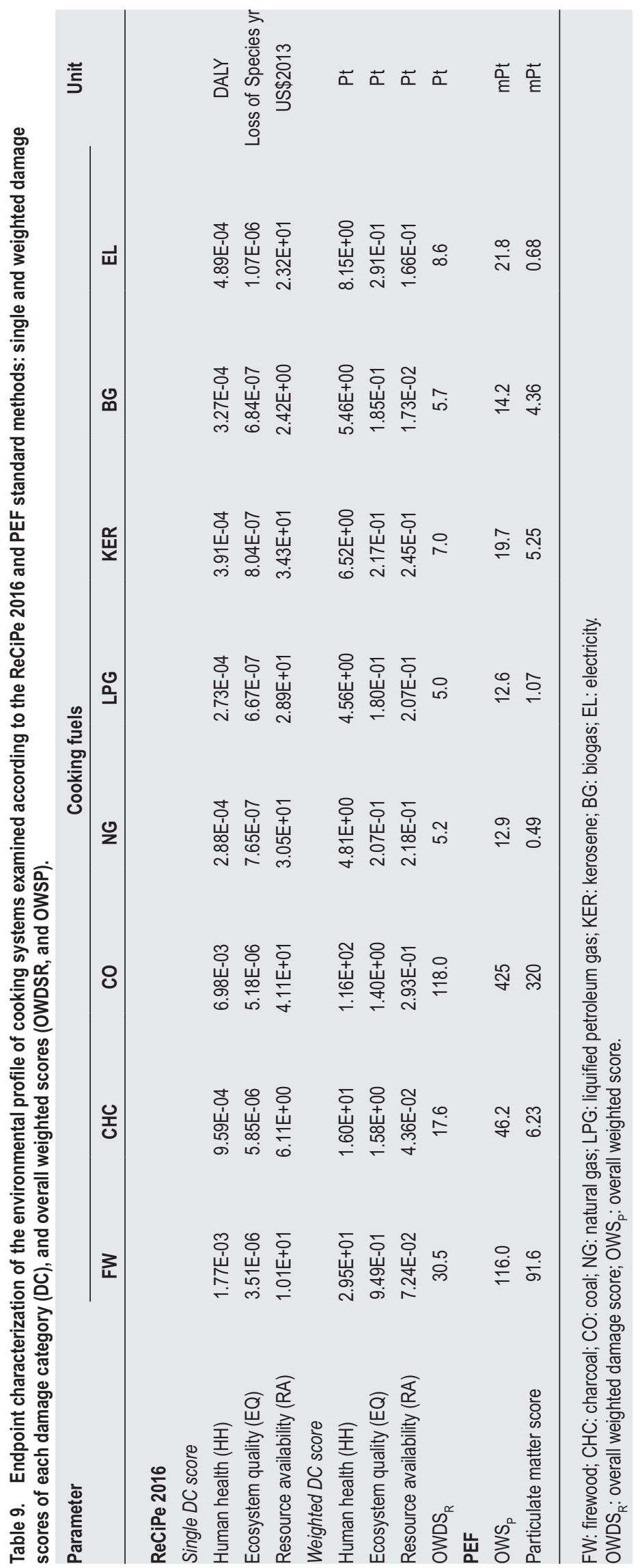




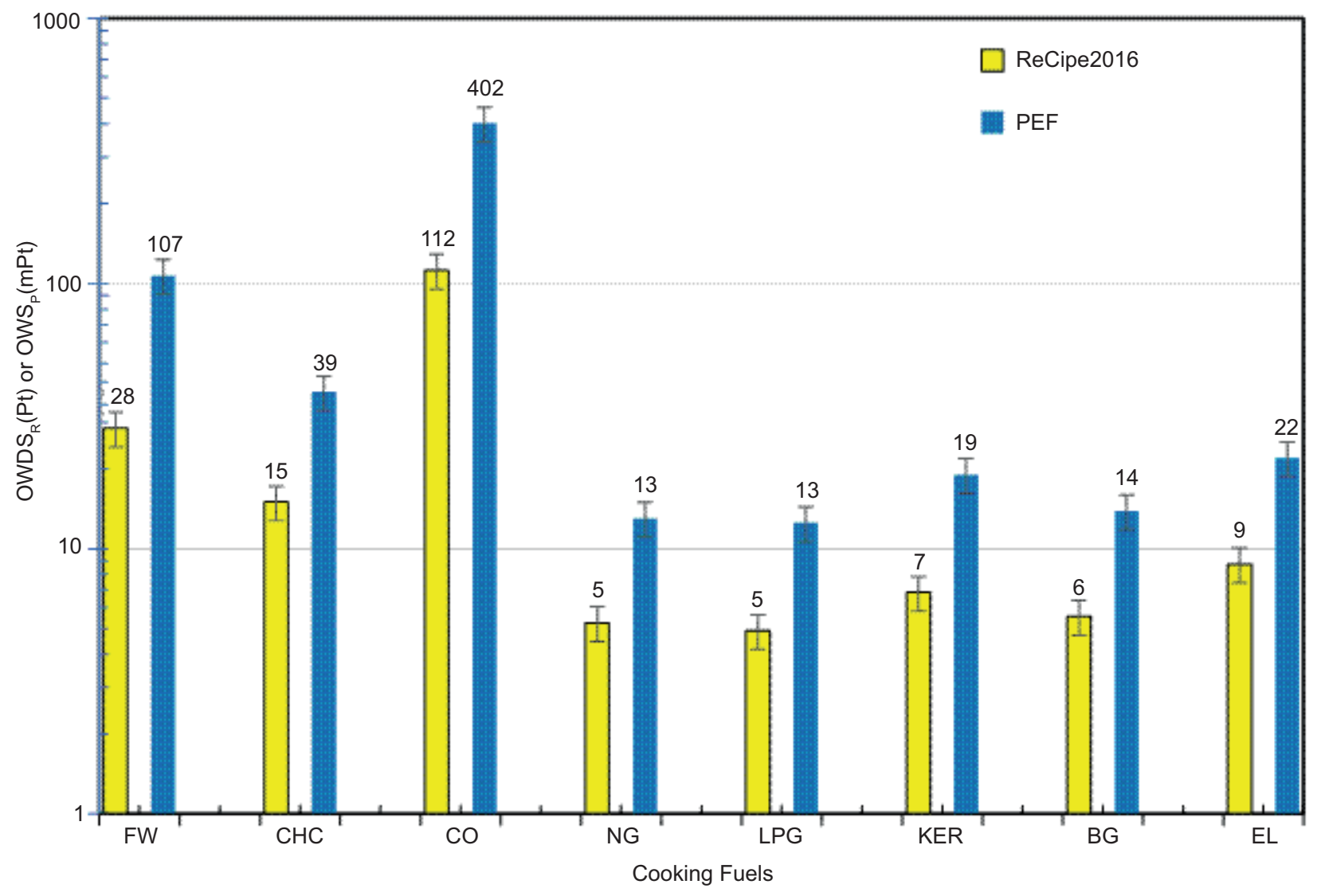

Figure 2. Comparison of environmental impact of different cooking systems examined using the overall weighted scores OWDS $_{R}$ and OWS $_{P}$ as estimated according to the ReCiPe 2016 end-point-Hierarchic $(H)$ version-Europe H/A and PEF standard methods, respectively: FW, firewood; CHC, charcoal; CO, coal; NG, natural gas; LPG, liquified petroleum gas; KER, kerosene; BG, biogas, and EL, electricity.

\section{Discussion of results and the future perspectives}

The main results of this LCA study pointed out quite similar environmental effects despite the different life cycle impact assessment methods used, and can be summarized as follows:

1. Among the cooking fuels used in the Italian context, the lowest environmental impact was associated with the use of NG and LPG if using the ReCiPe 2016 method, their overall weighted damaged scores being not statistically different at 5\% probability level. Such impact was, in turn, significantly smaller than that induced by burning biogas at $95 \%$ Confidence Level (CL) despite the fact that use of such a biofuel exerted just $8 \%$ of the damage to resource availability induced by other fossil fuels accounted for (Table 10). This was further corroborated by the fact that the database used excluded the infrastructure required to distribute biogas to final users (Table 7). According to the PEF method, LPG cookstoves exerted a lesser impact than that derived from NG and biogas cookstoves, probably because the average distance travelled by LPG bottles was assumed as short as $50 \mathrm{~km}$.

2. When using solid fuels derived from fossils (coal) and renewable (firewood and charcoal) sources, damage to the human health compartment increased by approximately 25 or six and three times, respectively, with respect to that caused by the cooking fuels mentioned above. This was similar to the previous findings from a few LCA studies relative to other countries, such as India (Singh et al., 2014), Ghana (Afrane and Ntiamoah, 2011, 2012) and remote communities in the Southeast Asia Pacific region (Aberilla et al., 2020) despite different LCIA methods used. Likewise, a recent meta-analysis of 50 studies from Africa, Asia, South and Latin America confirmed that indoor $\mathrm{PM}_{2.5}$ concentrations were very low if cooking is done with LPG and electricity (Pope et al., 2021). Finally, the LCA study of cooking fuel systems in India, China, Kenya and Ghana pointed out the primary requirement to reduce indoor PM formation, especially in China (its cooking fuel mix includes 31\% LPG, 29\% coal, 15\% firewood and 12\% crop residues) and India (its cooking fuel mix being 


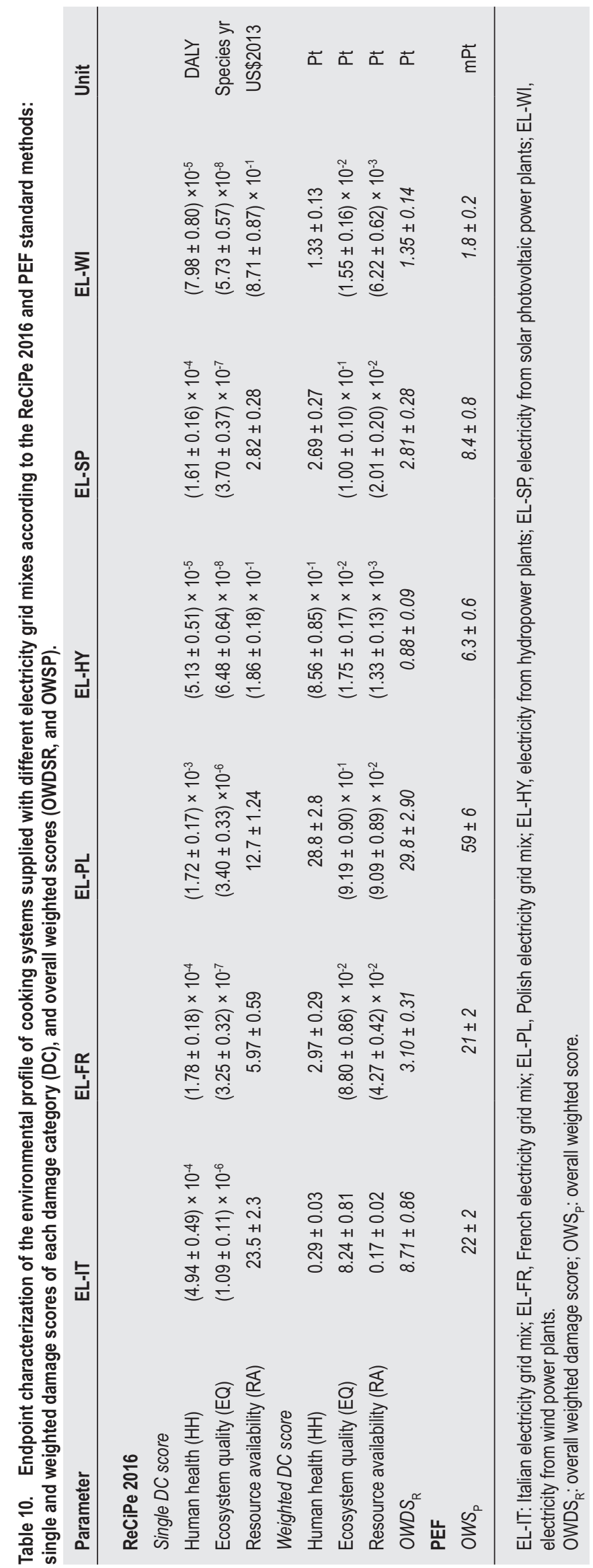

formed by $49 \%$ firewood, $25 \%$ LPG, $11 \%$ dung and $9 \%$ crop residues), and secondarily to replace traditional stoves with improved ones so as to allow the use of traditional cooking fuels in more appropriate forms and thus enhance their thermal efficiency and limit their environmental burden (Morelli et al., 2017). For instance, in China, substituting conventional honeycomb coal briquettes with coal powder would reduce the impact of climate change and PM formation by about $70 \%$ and $97 \%$, respectively (Morelli et al., 2017).

3. Electric cookstove accounted for more than $174 \%$ of overall weighted damage score of NG hob. This reflects the environmental impact of two typical cooking appliances, induction hob vs. gas hob and electric oven vs. gas oven, in Italian kitchens, as assessed by Favi et al. (2018) and Landi et al. (2019), respectively. Obviously, such unfavorable comparison stems from the nature of electricity grid mix in the Italian scenario, which is mainly based on fossil sources (Terna, 2020). Alternatively, use of French electricity grid mix, mainly established from nuclear energy, had the advantage of reducing damage to human health, ecosystem quality and resource availability by about $66 \%, 49 \%$ and $21 \%$, respectively. More favorable environmental impact would arise by using renewable electricity from hydro and wind plants. In this way, electric cooking would not only improve people's health but also avoid the consumption of any fossil energy source.

4. Electricity is currently the only means of cooking suitable for developing new-generation, energy-efficient home smart cookers. In fact, the prospective diffusion of low-cost, open-source platforms would in all probability reduce their selling price and thus promote their market penetration. Such platforms would, for instance, keep the selected cooking temperature practically constant or variable according to specific cooking programs, and shut the cooktop after preset period or as soon as the minimum core temperature is achieved. In this way, it would be possible to minimize both food cooking period and energy requirements. As an example, it is worth citing the eco-sustainable pasta cooking system developed by Cimini et al. (2021b). It consisted of a commercial 2-kW induction-plate hob, an induction stainless steel cooking pot, a stainless steel rod mixer piloted by a direct current electric motor welded to pot lid, a digital temperature sensor to monitor temperature of cooking water and a current sensor to register consumption of electric energy. All operations were accomplished via Arduino platform and an application installed in a smartphone with android system. It allowed short and long dry pastas to be cooked even at lower temperatures than the water boiling point at ambient pressure with as low as 2.7-3.2 L of cooking water per kg of dry pasta. Although the cooked pasta 
did not differ from that conventionally cooked at $100{ }^{\circ} \mathrm{C}$ with $10-\mathrm{L}$ water per $\mathrm{kg}$ of dry pasta in terms of chemico-physical quality parameters and ultrastructure, the pasta cooking energy requirement reduced from the default value of $2.8 \mathrm{kWh} / \mathrm{kg}$ to $0.45 \mathrm{kWh} /$ $\mathrm{kg}$, and the overall GHG emissions reduced to about one-sixth of those resulting from the use of average European home appliances.

5. Finally, even if the energy used for cooking represents just $6 \%$ of a household's typical energy consumption in the United States and EU-27 countries, such a percentage is quite high in some European, Asian and African countries. Above all, reduction of indoor and outdoor household air pollution and personal exposure to health damaging pollutants, such as PM and carbon monoxide, is a top-priority environmental goal.

\section{Conclusions}

After reviewing the basic characteristics of main cooking methods, appliances and fuels, and assessing environmental impact of a few household cookers fired by different fuels and electricity in the Italian scenario in compliance with the ReCiPe 2016 and PEF standard methods, it is pointed out that NG cookstove generates minimum indoor and outdoor air pollution. This finding was comforting, because the Italian cooking energy requirements are predominantly fulfilled by gas (69.2\%), although such cookers still rely on fossil energy sources.

To avoid finishing such sources and concurrently improving people's health, household cooking appliances must be replaced by new-generation smart-cooktops driven by hydropower or wind-power electricity, of course, on condition that global electricity generation from renewable energy sources is accelerated faster than done ever before.

\section{Acknowledgements}

This research was supported by the Italian Ministry of Instruction, University and Research within the research project entitled 'The Neapolitan pizza: processing, distribution, innovation and environmental aspects'; special grant PRIN 2017-prot. 2017SFTX3Y_001.

\section{References}

Aberilla J.M., Gallego-Schmid A., Stamford L., and Azapagic A. 2020. Environmental sustainability of cooking fuels in remote communities: life cycle and local impacts. Sci Total Environ. 713:136445. https://doi.org/10.1016/j.scitotenv.2019.136445
Afrane G. and Ntiamoah A. 2011. Comparative life cycle assessment of charcoal, biogas, and liquefied petroleum gas as cooking fuels in Ghana. J Indus Ecol. 15(4):539-549. https://doi. org/10.1111/j.1530-9290.2011.00350.x

Afrane G. and Ntiamoah A. 2012. Analysis of the life-cycle costs and environmental impacts of cooking fuels used in Ghana. Appl Energy. 98:301-306. https://doi.org/10.1016/j. apenergy.2012.03.04

Anozie A.N., Bakare A.R., Sonibare J.A., and Oyebisi T.O. 2007. Evaluation of cooking energy cost, efficiency, impact on air pollution and policy in Nigeria. Energy. 32:1283-1290. https://doi. org/10.1016/j.energy.2006.07.004

Appropedia. 2008. Ashden Awards. CleanCook ethanol stove. Available at: https://www.appropedia.org/CleanCook_ethanol_ stove (accessed: 19 Jan 2022).

Apurva. 2016. Tandoors, burning of solid waste adding to dirty Delhi air: IIT Study. Indian Express. Available at: https://indianexpress.com/article/india/india-news-india/tandoors-burningof-solid-waste-adding-to-dirty-delhi-air-iit-study/ (accessed: 13 Dec 2021).

Arenas J.M. 2007. Design, development and testing of a portable parabolic solar kitchen. Renew Energy. 32:257-266. https://doi. org/10.1016/j.renene.2006.01.013

Aro E.M. 2016. From first generation biofuels to advanced solar biofuels. Ambio. 45(Suppl 1):S24-S31. https://doi.org/10.1007/ s13280-015-0730-0

Barratt N. 2021. Different oven types explained! Available at: https:// www.canstarblue.co.nz/appliances/ovens/different-types-ofovens-explained/ (accessed: 2 Dec 2021).

Bedoić R., Ćosić B., Pukšec T., and Duić N. 2020. Anaerobic digestion of agri-food by-products. In Holden N.M., Wolfe M.L., Ogejo J.A., and Cummins E.J. (Eds.) Introduction to Biosystems Engineering. American Society of Agricultural and Biological Engineers (ASABE) in association with Virginia Tech, Blacksburg, VA, pp. 1-23. Available at: https://vtechworks.lib. vt.edu/bitstream/handle/10919/93254/Anaerobic_Digestion. pdf?sequence=27\&isAllowed=y (accessed: 11 Dec 2021). https:// doi.org/10.21061/IntroBiosystemsEngineering/Anerobic_Digestion

Benka-Coker M.L., Tadele W., Milano A., Getaneh D., and Stokes H. 2018. A case study of the ethanol CleanCook stove intervention and potential scale-up in Ethiopia. Energy Sustain Develop. 46:53-64. https://doi.org/10.1016/j.esd.2018.06.009

Bertrand E., Vandenberghe L.P.S., Soccol C.R., Sigoillot J.C., and Faulds C. 2016. First generation bioethanol. In: Soccol C., Brar S., Faulds C., and Ramos L. (Eds.) Green fuels technology. Green Energy and Technology. Springer, Cham, Denmark. https://doi.org/10.1007/978-3-319-30205-8_8

Bevilacqua M., Braglia M., Carmignani G., and Zammori F.A. 2007. Life cycle assessment of pasta production in Italy. J Food Qual. 30:932-952. https://doi.org/10.1111/j.1745-4557.2007.00170.x

British Standards Institution (BSI). 2011. PAS 2050:2011. Specification for the Assessment of the Life Cycle Greenhouse Gas Emissions of Goods and Services. British Standards Institution, London.

Carlsson-Kanyama A. and Boström-Carlsson K. 2001. Energy Use for Cooking and Other Stages in the Life Cycle of Food. A Study 
of Wheat, Spaghetti, Pasta, Barley, Rice, Potatoes, Couscous and Mashed Potatoes. Report No. 160. Stockhoms Universitet, Stockholm, Sweden.

Cibelli M., Cimini A., Cerchiara G., and Moresi M. 2021. Carbon footprint of different methods of coffee preparation. Sustain Prod Consump. 27:1614-1625. https://doi.org/10.1016/j.spc.2021.04.004

Cimini A., Cibelli M., and Moresi M. 2019. Cradle-to-grave carbon footprint of dried organic pasta: Assessment and potential mitigation measures. J Sci Food Agricul. 99:5303-5318 https://doi. org/10.1002/jsfa.9767.

Cimini A., Cibelli M., and Moresi M. 2020. Development and assessment of a home eco-sustainable pasta cooker. Food Bioprod Proc. 122:291-302. https://doi.org/10.1016/j.fbp.2020.05.009

Cimini A., Cibelli M., and Moresi M. 2021a. Environmental impact of pasta. In Galanakis C. (Ed.) Environmental Impact of AgroFood Industry and Food Consumption. Chp. 5; pp. 101-127. Academic Press, San Diego, CA. https://doi.org/10.1016/ B978-0-12-821363-6.00005-9

Cimini A., Cibelli M., Taddei A.R., and Moresi M. 2021b. Effect of cooking temperature on cooked pasta quality and sustainability. J Sci Food Agricul. 101:4946-4958. https://doi.org/10.1002/ jsfa.11138

Cimini A. and Moresi M. 2017. Energy efficiency and carbon footprint of home pasta cooking appliances. J Food Eng. 204:8-17. https://doi.org/10.1016/j.jfoodeng.2017.01.012

Climate Technology Center \& Network (CTCN). 2017. Ethanol cook stoves. Available at: https://www.ctc-n.org/technologies/ ethanol-cook-stoves (accessed: 19 Jan 2022).

Costagliola M.A., De Simio L., Iannaccone S., and Prati M.V. 2013. Combustion efficiency and engine out emissions of a S.I. engine fueled with alcohol/gasoline blends. Appl Energy. 111:11621171. https://doi.org/10.1016/j.apenergy.2012.09.042

Darlami H.B., Ale B.B., and Pokharel G.R. 2019. Experimental analysis of thermal efficiency of mud improved cookstove with variation of different parameters and economic analysis. J Inst Eng. 15(3):385-392. https://doi.org/10.3126/jie.v15i3.32228

Ecoinvent. (2020) Ecoinvent v3.7.1. Available at: https://ecoinvent. org/the-ecoinvent-database/data-releases/ecoinvent-3-7-1/ (accessed: 11 Feb 2022).

Elduque D., Javierre C., Pina C., Martínez E., and Jiménez E. 2014. Life cycle assessment of a domestic induction hob: Electronic boards. J Clean Prod. 76:74-84. https://doi.org/10.1016/j. jclepro.2014.04.009

European Commission (EC). 2010. Commission Regulation (EU) No. 97/2010, "Entering a name in the register of traditional specialities guaranteed [Pizza Napoletana (TSG)]." Off J EU. L 34, 05 February. Available at: https://eur-lex.europa.eu/legal-content/ EN/TXT/HTML/?uri=OJ:L:2010:034:FULL (accessed: 13 Dec 2021).

European Commission (EC). 2018a. Directive (EU) 2018/2001 of the European Parliament and of the Council of 11 December 2018 on the promotion of the use of energy from renewable sources. Off J EU. L 328/82, 21 December. Available at: https:// eur-lex.europa.eu/legal-content/EN/TXT/PDF/?uri=CELEX: 32018L2001\&from=fr (accessed: $24 \operatorname{Jan} 2022)$.
European Commission (EC). 2018b. Product Environmental Footprint Category Rules Guidance-Version 6.3. European Commission, Brussels, Belgium. Available at: https://eplca.jrc. ec.europa.eu/permalink/PEFCR_guidance_v6.3-2.pdf (accessed: 18 Dec 2021).

Eurostat. 2021a. Energy consumption in households. Available at: https://ec.europa.eu/eurostat/statistics-explained/index.php? title=Energy_consumption_in_households\#Energy_products_ used_in_the_residential_sector (accessed: 20 Nov 2021).

Eurostat. 2021b. Population projections in the EU. Available at: https://ec.europa.eu/eurostat/statistics-explained/index.php?oldid=497115\#Population_projections (accessed: 4 Dec 2021).

Fantke P., Evans J., Hodas N., Apte J., Jantunen M., Jolliet O., and McKone T.E. 2016. Health impacts of fine particulate matter. In Frischknecht R. and Jolliet O. (Eds.) Global Guidance for Life Cycle Impact Assessment Indicators. Vol. 1, pp 76-99. UNEP/ SETAC Life Cycle Initiative, Paris, France.

Favi C., Germani M., Landi D., Mengarelli M., and Rossi M. 2018. Comparative life cycle assessment of cooking appliances in Italian kitchens. J Clean Prod. 186:430-449. https://doi. org/10.1016/j.jclepro.2018.03.140

Florida Power \& Light Co. 2003. Natural gas specs sheet. Available at: https://www.naesb.org/pdf2/wgq_bps100605w2.pdf (accessed: 19 Jan 2022).

Foster C., Green K., Blea M., Dewick P., Evans B., Flynn A., and Mylan J. 2006. Environmental Impacts of Food Production and Consumption. Report to the Department of the Environment, Food, and Rural Affairs (DEFRA). Manchester Business School London.

Francescato V., Antonini E., and Zuccoli Bergomi L. 2008. Wood Fuels Handbook. Italian Agroforestry Energie Association (AIEL), Legnaro (PD), Italy. Available at: https://www.yumpu. $\mathrm{com} / \mathrm{pt} /$ document/read/2571080/wood-fuels-handbook-biomasstradecentres (accessed: 6 Dec 2021).

Frankowska A., Schmidt Rivera X., Bridle S.L., Kluczkovski A., da Silva J., Martins C., Rauber F., Levy R.B., Cook J., and Reynolds C. 2020. How home cooking methods and appliances affect the GHG emissions of food. Nature Food. 1:787-791. https://doi.org/10.1038/s43016-020-00200-w

Fullerton D.G., Bruce N., and Gordon S.B. 2008. Indoor air pollution from biomass fuel smoke is a major health concern in the developing world. Trans Royal Soc Trop Med Hygiene. 102:843851. https://doi.org/10.1016/j.trstmh.2008.05.028

Gould C.F. and Urpelainen J. 2018. LPG as a clean cooking fuel: Adoption, use, and impact in rural India. Energy Policy. 122:395-408. https://doi.org/10.1016/j.enpol.2018.07.042

Hager T.J. and Morawicki R. 2013. Energy consumption during cooking in the residential sector of developed nations: A review. Food Policy. 40:54-63. https://doi.org/10.1016/j. foodpol.2013.02.003

Huijbregts M.A.J., Steinmann Z.J.N., Elshout P.M.F., Stam G., Verones F., Vieira M., Zijp M., Hollander A., and van Zelm R. 2017. ReCiPe 2016: A harmonised life cycle impact assessment method at midpoint and endpoint level. Int J Life Cycle Assess. 22:138-147. https://doi.org/10.1007/s11367-016-1246-y 
Huijbregts M.A.J., Steinmann Z.J.N., Elshout P.M.F., Verones F., Vieira M.D.M., Hollander A., Zijp M., van Zelm R., and Stam G. 2016. ReCiPe2016: A Harmonized Life Cycle Impact Assessment Method at Midpoint and Endpoint LevelS. Report I: Characterization. RIVM Report 2016. National Institute for Public Health and the Environment, Bilthoven, the Netherlands. https://doi.org/10.1007/s11367-016-1246-y

Igo S.W., Kokou N., Compaoré A., Kalifa P., Sawadogo G.L., and Namoano D. 2020. Experimental analysis of the thermal performance of a metal fired-wood oven. Iranian (Iranica) J Energy Environ. 11(3):225-230. https://doi.org/10.5829/IJEE. 2020.11.03.08

International Energy Agency (IEA). 2018. World energy outlook 2018. Available at: https://iea.blob.core.windows.net/ assets/77ecf96c-5f4b-4d0d-9d93-d81b938217cb/World_ Energy_Outlook_2018.pdf (accessed: 13 Dec 2021).

International Energy Agency (IEA). 2019. World energy outlook 2019. Available at: https://iea.blob.core.windows.net/ assets/98909c1b-aabc-4797-9926-35307b418cdb/WEO2019free.pdf (accessed: 13 Dec 2021).

International Energy Agency (IEA) and the World Bank. 2014. Sustainable Energy for All 2013-2014: Global Tracking Framework Report. World Bank, Washington, DC. https://doi. org/10.1596/978-1-4648-0200-3.

International Organization for Standardization (ISO). 2006 a. 14040-Environmental Management e Life Cycle AssessmentPrinciples and Framework. International Organization for Standardization, Genève, $\mathrm{CH}$.

International Organization for Standardization (ISO). $2006 \mathrm{~b}$. 14044-Environmental Management-Life Cycle AssessmentRequirements and Guidelines. International Organization for Standardization, Genève, $\mathrm{CH}$.

International Renewable Energy Agency (IRENA). 2017. Biogas for Domestic Cooking: Technology Brief. International Renewable Energy Agency, Abu Dhabi. Available at: https://irena.org/-/ media/Files/IRENA/Agency/Publication/2017/Dec/IRENA_ Biogas_for_domestic_cooking_2017.pdf (accessed: 1 Jan 2022).

Iodice P., Langella G., and Amoresano A. 2018. Ethanol in gasoline fuel blends: Effect on fuel consumption and engine out emissions of SI engines in cold operating conditions. Appl Therm Eng. 130:1081-1089. https://doi.org/10.1016/j. applthermaleng.2017.11.090

Jeswani H.K., Chilvers A., and Azapagic A. 2020. Environmental sustainability of biofuels: A review. Proc Royal Soc A. 476:20200351. https://doi.org/10.1098/rspa.2020.0351

Jungbluth N., Kollar M., and Koß V. 1997. Life cycle inventory for cooking. Some results for the use of liquefied petroleum gas and kerosene as cooking fuels in India. Energy Policy. 25(5):471-480. https://doi.org/10.1016/S0301-4215(97)00022-0

Kang Q., Appels L., Tan T., and Dewil R. 2014. Bioethanol from lignocellulosic biomass: Current findings determine research priorities. Sci World J. 2014:Arte ID 298153, 13 p. http://dx.doi. org/10.1155/2014/298153

Lakshmi S., Chakkaravarthi A., Subramanian R., and Singh V. 2007. Energy consumption in microwave cooking of rice and its comparison with other domestic appliances. J Food Eng. 78(2):715-722. https://doi.org/10.1016/j.jfoodeng.2005.11.011

Landi D., Consolini A., Germani M., and Favi C. 2019. Comparative life cycle assessment of electric and gas ovens in the Italian context: An environmental and technical evaluation. J Clean Prod. 221:189-201. https://doi.org/10.1016/j.jclepro.2019.02.196

Lima F.D.M., Pérez-Martínez P.J., de Fatima Andrade M., Kumar P., and de Miranda R.M. 2020. Characterization of particles emitted by pizzerias burning wood and briquettes: A case study at Sao Paulo, Brazil. Environ Sci Pollution Res. 27:35875-35888. https://doi.org/10.1007/s11356-019-07508-6.

Makavana J.M., Agravat V.V., Balas P.R., Makwana P.J., and Vyas V.G. 2018. Engineering properties of various agricultural residue. Int J Curr Microbiol App. Sci. 7(6):2362-2367. https://doi. org/10.20546/ijcmas.2018.706.282

Manfredi S., Allacker K., Chomkhamsri K., Pelletier N., and Maia de Souza D. 2012. Product Environmental Footprint (PEF) Guide. European Commission, Ispra, Italy.

Manhiça F.A., Lucas C., and Richards T. 2012. Wood consumption and analysis of the bread baking process in wood-fired bakery ovens. Appl Ther Eng. 47:63-72. https://doi.org/10.1016/j. applthermaleng.2012.03.007

Manzetti S. and Andersen O. 2015. A review of emission products from bioethanol and its blends with gasoline. Background for new guidelines for emission control. Fuel. 140:293-301. https:// doi.org/10.1016/j.fuel.2014.09.101

Martínez-Gómez J., Ibarra D., Villacis S., Cuji P., and Cruz P.R. 2016. Analysis of LPG, electric and induction cookers during cooking typical Ecuadorian dishes into the national efficient cooking program. Food Policy. 59:88-102. https://doi.org/10.1016/j. foodpol.2015.12.010

McGee H. 2004. On Food and Cooking - The Science and Lore of the Kitchen. Scribner, New York, NY.

Mehetre S.A., Panwar N.L., Sharma D., and Kumar H. 2017. Improved biomass cookstoves for sustainable development: A review. Renew Sustain Energy Rev. 73:672-687. https://doi. org/10.1016/j.rser.2017.01.150

Morelli B., Cashman S., Rodgers M. 2017. Life Cycle Assessment of Cooking Fuel Systems in India, China, Kenya and Ghana. Report No. EPA/600/R-17/225. US Environmental Protection Agency, Washington, DC. Available at: https://cfpub.epa.gov/si/si_public_record_Report.cfm?Lab=NRMRL\&dirEntryId=339679 (accessed: 30 Dec 2021).

Mukunda H.S. 2009. Understanding Combustion, 2nd edition. Orient Blackswan, New Delhi, India.

Myhre G., Shindell D., Bréon F.-M., Collins W., Fuglestvedt J., Huang J., Koch D., Lamarque J.-F., Lee D., Mendoza B., Nakajima T., Robock A., Stephens G., Takemura T., and Zhang H. 2013. Anthropogenic and natural radiative forcing. Ch. 8. In Stocker T.F., Qin D., Plattner G.-K., Tignor M., Allen S.K., Boschung J., Nauels A., Xia Y., Bex V., Midgley P.M. (Eds.) Climate Change 2013: The Physical Science Basis. Contribution of Working Group I to the Fifth Assessment Report of the Intergovernmental Panel on Climate Change, pp. 731-738. Cambridge University Press, Cambridge, UK. 
Available at: https://www.ipcc.ch/site/assets/uploads/2018/02/ WG1AR5_Chapter08_FINAL.pdf (accessed: 18 Dec 2021).

Nielsen H. 2003. Cooking food in ovens and stoves. Available at: http://www.lcafood.dk/ (accessed: 25 Nov 2021).

Okino J., Komakech A.J., Wanyama J., Ssegane H., Olomo E., and Omara T. 2021. Performance characteristics of a cooking stove improved with sawdust as an insulation material. J Renew Energy, vol. 2021, Art ID 9969806: 1-12. https://doi. org/10.1155/2021/9969806

Okoko A., Wymann von Dach S., Reinhard J., Kiteme B., and Owuor S. 2018. Life cycle costing of alternative value chains of biomass energy for cooking in Kenya and Tanzania. J Renew Energy. 2018(Article ID 3939848):1-12. https://doi. org/10.1155/2018/3939848

Okusanya M.A., Ibrahim G.W., and Ogunlade C.B. 2019. The use of ethanol gel cook-stove as a more accessible alternative cooking energy. Int J Eng Sci Invent. 8(10):15-22. www.ijesi.org

Pandey S., Goswami S., Saini P., Powar S., and Dhar A. 2021. Hybrid electrical-solar oven: A new perspective. In Tyagi H., Chakraborty P.R., Powar S., Agarwal A.K. (eds.) New Research Directions in Solar Energy Technologies. Energy, Environment, and Sustainability, pp. 237-255. Springer, Singapore. https://doi. org/10.1007/978-981-16-0594-9_8

Pope D., Johnson M., Fleeman N., Jagoe K., Duarte R., Maden M., Ludolph R., Bruce N., Shupler M., Adair-Rohani H., and Lewis J. 2021. Are cleaner cooking solutions clean enough? A systematic review and meta-analysis of particulate and carbon monoxide concentrations and exposures. Environ Res Lett. 16:083002. https://doi.org/10.1088/1748-9326/ac13ec

Pratiti R., Vadala D., Kalynych Z., and Sud P. 2020. Health effects of household air pollution related to biomass cook stoves in resource limited countries and its mitigation by improved cookstoves. Environ Res. 186:109574. https://doi.org/10.1016/j. envres.2020.109574

Probert D. and Newborough M. 1985. Designs, thermal performances and other factors concerning cooking equipment and associated facilities. Appl Energy. 21:81-222. https://doi. org/10.1016/0306-2619(85)90069-8

Rajvanshi A.K., Patil S.M., and Mendoca B. 2004. Development of Stove Running on Low Ethanol Concentration. Nimbkar Agricultural Research Institute (NARI), Maharashtra, India.

Rasoulkhani M., Ebrahimi-Nik M., Abbaspour-Fard M.H., and Rohani A. 2018. Comparative evaluation of the performance of an improved biomass cookstove and the traditional stoves of Iran. Sustain Environ Res. 28(6):438-443. https://doi. org/10.1016/j.serj.2018.08.001

Rosenthal J., Quinn A., Grieshop A.P., Pillarisetti A., and Glass R.I. 2018. Clean cooking and the SDGs: Integrated analytical approaches to guide energy interventions for health and environment goals. Energy Sustain Develop. 42:152-159. https://doi. org/10.1016/j.esd.2017.11.003

Sala S., Cerutti A.K., and Pant R. 2018. Development of a Weighting Approach for the Environmental Footprint. Publications Office, European Union, Luxembourg. http://dx.doi. org/10.2760/945290. Available at: https://publications.jrc.ec.europa.eu/repository/handle/JRC106545 (accessed: 18 Dec 2021).
Sala S., Crenna E., Secchi M., and Pant R. 2017. Global Normalisation Factors for the Environmental Footprint and Life Cycle Assessment. JRC Scientic Report. Publications Office, European Union, Luxembourg. http://dx.doi.org/10.2760/88930 Available at: https://publications.jrc.ec.europa.eu/repository/ handle/JRC109878 (accessed: 18 Dec 2021).

Shen J., Zhu S., Liu X., i Zhang H., and Tan J. 2010. The prediction of elemental composition of biomass based on proximate analysis. Energy Convers Manag. 51:983-987.

Singh P., Gundimeda H., and Stucki M. 2014. Environmental footprint of cooking fuels: A life cycle assessment of ten fuel sources used in Indian households. Int J Life Cycle Assess. 19:10361048. https://doi.org/10.1007/s11367-014-0699-0

Singh B. and Highway D. 2016. What is your restaurant's carbon footprint? Available at: https://www.pizzamarketplace.com/articles/what-is-your-restaurants-carbon-footprint/ (accessed: 13 Dec 2021).

Stokes H. and Ebbeson B. 2005. Project Gaia: Commercialising a new stove and new fuel in Africa. Boiling Point. 50:31-33.

Terna. 2020. Dati statistici sull'energia elettrica in Italia. Available at: https://www.terna.it/it/sistema-elettrico/statistiche/pubblicazionistatistiche (accessed: 24 Jan 2022).

Theodoridis S. 2015. Monte Carlo methods. In Machine Learning. A Bayesian and Optimization Perspective, Chp. 14, pp 707-744. Academic Press, London. https://doi.org/10.1016/ B978-0-12-801522-3.00014-8

Thoday K., Benjamin P., Gan M., and Puzzolo E. 2018. The mega conversion program from kerosene to LPG in Indonesia: Lessons learned and recommendations for future clean cooking energy expansion. Energy Sustain Dev J Int Energy Initiative. 46:71-81. https://doi.org/10.1016/j.esd.2018.05.011

Thompson M., Ellis R., and Wildavsky A. 1990. Cultural Theory. Westview Press, Boulder, CO.

United Nations Development Program (UNDP). 2021. What are the sustainable development goals? Available at: https://www.undp. org/sustainable-development-goals (accessed: 29 Dec 2021).

US Environmental Protection Agency (EPA). 1998. Natural gas combustion. Available at: https://www3.epa.gov/ttnchie1/ap42/ ch01/final/c01s04.pdf (accessed: 10 Dec 2021).

van Zelm R., Preiss P., Van Goethem T., van Dingenen R., and Huijbregts M.A.J. 2016. Regionalized life cycle impact assessment of air pollution on the global scale: Damage to human health and vegetation. Atmos Environ. 134:129-137. https://doi. org/10.1016/j.atmosenv.2016.03.044.

Vargas-Moreno J.M., Callejón-Ferre A.J., Pérez-Alonso J., and Velázquez-Martí B. 2012. A review of the mathematical models for predicting the heating value of biomass materials. Renew Sustain Energy Rev. 16:3065-3083. https://doi.org/10.1016/j. rser.2012.02.054

Vassilev S.V., Baxter D., Andersen L.K., and Vassileva C.G. 2010. An overview of the chemical composition of biomass. Fuel. 89:913933. https://doi.org/10.1016/j.fuel.2009.10.022

Wikipedia. 2021a. Improved cookstove. Available at: https://en. wikipedia.org/wiki/Improved_cookstove (accessed: 26 Nov 2021).

Wikipedia. 2021b. Gas stove. Available at: https://en.wikipedia.org/ wiki/Gas_stove (accessed: 29 Nov 2021). 
Wikipedia. 2021c. Electric stove. Available at: https://en.wikipedia. org/wiki/Electric_stove (accessed: 26 Nov 2021).

Wikipedia. 2021d. Charcoal. Available at: https://en.wikipedia.org/ wiki/Charcoal (accessed: 9 Dec 2021).

Wollele M.B. 2020. Quantifying energy losses on electric cooking stove. Int J Eng Res Technol. 9(5):753-756. https://doi. org/10.17577/IJERTV9IS050577

World Health Organization (WHO). 2018. Ambient (outdoor) air pollution. Available at: http://www.who.int/mediacentre/factsheets/fs313/en/index.html (accessed: 13 Dec 2021).

World Health Organization (WHO). 2021. Household air pollution and health. Available at: https://www.who.int/news-room/factsheets/detail/household-air-pollution-and-health (accessed: 29 Dec 2021).

Wrangham R. 2009. Catching Fire: How Cooking Made Us Human. Basic Books, New York, NY.
Wrangham R. and Conklin-Brittain N. 2003. Cooking as a biological trait. Comp Biochem Physiol Mol Integ Physiol. 136(1):35-46. https://doi.org/10.1016/S1095-6433(03)00020-5

Wright C., Sathre R., and Buluswar S. 2020. The global challenge of clean cooking systems. Food Secur. 12:1219-1240. https://doi. org/10.1007/s12571-020-01061-8

Xu Z., Sun D.-W., Zhang Z., and Zhu Z. 2015. Research developments in methods to reduce carbon footprint of cooking operations: A review. Trends Food Sci Technol. 44:49-57. https://doi. org/10.1016/j.tifs.2015.03.004

Zuzarte F. 2007. Ethanol for cooking-Feasibility of Small-Scale Ethanol Supply and Its Demand as a Cooking Fuel: Tanzania Case Study. KTH School of Energy and Environmental Technology, Heat and Power Technology, Stockholm, Sweden. 